Universidade de São Paulo

Instituto de Física

\title{
ESTUDO DAS PROPRIEDADES ÓTICAS E ELÉTRICAS DE FILMES FINOS DE
}

ÓXIDO DE ZINCO

\author{
Renato Vasconcelos Coura Soares
}

Orientador: Prof. Dr. José Fernando Diniz Chubaci

Dissertação de mestrado apresentada ao Instituto de Física para a obtenção do título de Mestre em Ciências

Banca Examinadora:

Prof. Dr. José Fernando Diniz Chubaci (IFUSP)

Prof. Dr. João Francisco Justo Filho (Poli-USP)

Profa. Dra. Eliane de Fátima Chinaglia (FEI/SBCampo)

São Paulo

2018 


\section{FICHA CATALOGRÁFICA \\ Preparada pelo Serviço de Biblioteca e Informação do Instituto de Física da Universidade de São Paulo}

Soares, Renato Vasconcelos Coura

Estudo das propriedades óticas e elétricas de filmes finos de óxido de zinco. São Paulo, 2018.

Dissertação (Mestrado) - Universidade de São Paulo. Instituto de Física. Depto. de Física Nuclear

Orientador: Prof. Dr. José Fernando Diniz Chubaci

Área de Concentração: Física da Matéria Condensada.

Unitermos: 1. Óxido de zinco; 2. Magnetron sputtering; 3. Estrutura dos sólidos; 4. Band-gap; 5. Filmes finos.

USP/IF/SBI-043/2018 


\author{
University of São Paulo \\ Institute of Physics
}

\title{
STUDY OF THE OPTICAL AND ELECTRICAL PROPERTIES OF ZINC OXIDE THIN FILMS
}

\author{
Renato Vasconcelos Coura Soares
}

Advisor: Prof. Dr. José Fernando Diniz Chubaci

Master's Dissertation presented to the Institute of

Physics to obtain the title of Master of science

Examining Committee:

Prof. Dr. José Fernando Diniz Chubaci (IFUSP)

Prof. Dr. João Francisco Justo Filho (Poli-USP)

Profa. Dra. Eliane de Fátima Chinaglia (FEI/SBCampo)

São Paulo

2018 
Dedico este trabalho a minha familia, sem eles eu nada seria. 


\section{Agradecimentos}

Agradeço em primeiro lugar a minha mãe Helena Aparecida Coura Soares, sendo a mulher dedicada que é, lutou para que seus 3 filhos tivessem uma educação diferente daquela que estaríamos condicionados na periferia de Itaquaquecetuba. Deu todo o suporte para que pudéssemos nos preocupar só com a nossa formação acadêmica, por mais que a questão financeira não ajudasse. "A senhora é uma rainha".

Agradeço ao meu pai Custodio Soares, um homem simples que me mostrou que não precisamos de grandes luxos para se viver feliz, sempre encontrando um meio de conciliar suas ideologias com uma estrutura social que muitas vezes não conciliava com o que ele achava certo.

Ao meu padrinho Mauro Isao, por sua grande contribuição com a minha formação desde quando eu era criança. Seu auxilio em sempre instigar os porquês da vida, me fizeram querer buscar respostas que culminaram na minha formação na área da ciência.

As minhas irmãs Sarah Aparecida Coura Soares e Cintia Dalila Soares, que com seus exemplos de vida, pude ver que é possível conquistar sonhos por mais distantes que possam aparecer.

Ao meu grande companheiro de trajetória Pedro Oliveira de Souza. Estamos em caminhos próximos à mais de 10 e sua amizade contribui com a formação do meu caráter. Nossas inúmeras conversas e confidências me ajudam a enxergar melhor os problemas que aparecem no meu caminho.

Aos grandes amigos que adquiri durante a graduação, em especial à Raffaela de Rosa, Arthur Lopes, Bianca Mendonça, Danilo Vieira, Moises Medeiros. Pessoas que levo no coração, que sem eles certamente este trabalho não teria acontecido.

Agradeço aos meus irmãos do time de rugby Demônios de Maxwell. Sempre me apoiando nos momentos mais difíceis.

A todos os colegas de moradia estudantil que tive durante esses anos. Em especial aos moradores do apartamento A1 - 504, onde passei grandes momentos da minha vida.

Agradeço ao meu orientador Prof. Dr. Jose Fernando Diniz Chubaci, pela oportunidade de trabalho, pelas conversas e por sempre me incentivar.

À todos técnicos que me ajudaram nas medições de dados e nas análises. Em especial a Profa. Dra. Marina Sparvoli de Medeiros, pelas dicas e conselhos. 
À SAS (serviço de assistência social), que com o apoio de moradia cedido a mim tornou esse trabalho possível.

Ao Prof. Dr. Ronaldo Mansano e ao Laboratório de Sistemas Integráveis (LSI) pela logística e infraestrutura fornecida para a realização deste trabalho.

Ao suporte financeiro parcial da Fundação de Amparo à Pesquisa do Estado de São Paulo e do Office of Naval Research - Global (ONR-G).

E a todos que de alguma forma, direta ou indiretamente, contribuíram com a realização deste trabalho. 
"Busquem conhecimento".

(E.T.Bilu) 


\section{Resumo}

O desenvolvimento de filmes finos e nanotecnologia tem proporcionado imensos avanços nas áreas cientificas e tecnológicas. A nanotecnologia, em sua essência, não pode ser considerada como uma simples redução das dimensões das propriedades dos materiais. Na verdade surgem novas propriedades que não podem ser caracterizadas por técnicas convencionais. Assim surgiram novos sistemas que são empregados na identificação destas novas propriedades e características. Muitas vezes os avanços tecnológicos que podem ser observados no dia a dia são frutos de pesquisas que foram recentemente realizadas. Nesse contexto, a demanda por óxidos condutores transparentes (Transparent conductive oxide - TCO) para aplicações em optoeletrônica, tais como painéis de toque, monitores de tela plana, diodos orgânicos emissores de luz (OLEDs) e outros dispositivos móveis, tem aumentado continuamente e se enquadram neste desenvolvimento. O objetivo desse trabalho é analisar filmes finos de óxido de zinco produzidos por magnetron sputtering. Os filmes finos foram analisados por: "Rutherford backscatering spectroscopy" (RBS), $\mathrm{CxV}, \quad \mathrm{IxV}$, Efeito Hall, Interferômetria e Espectofotômetria UV-Vis-NIR. Os filmes de óxido de zinco que possuem as melhores características de um TCO foram os filmes depositados à baixas potências com os menores tempo de deposição. 


\begin{abstract}
The development of thin films and nanotechnology has provided immense advances in scientific and technological areas. Nanotechnology, in its essence, cannot be considered as a simple reduction of dimensions and scaling of material properties. In fact, new properties that arise cannot be characterized by conventional techniques. Thus, new systems have emerged which are employed in the identification of these new properties and characteristics. Often the technological advances that can be observed in the day to day are fruits of researches that have been recently developed. Demand for transparent conductive oxides (TCO) for optoelectronic applications, such as touch panels, flat panel monitors, organic light emitting diodes (OLEDs) and other mobile devices, has continuously increased and fits into this development. The objective of this work is to analyze thin films of zinc oxide, induced by magnetron sputtering. We look for which zinc oxide film have the best characteristics for a TCO. After this analysis we have conditions to determine which were the best deposit parameters for the construction of the zinc oxide film. The characterizations will be carried out through measurements of: Rutherford backscattering spectroscopy (RBS), CxV, IxV, Hall Effect, Interferometry and UVVis-NIR Spectrophotometry. The zinc oxide films that have shown the best characteristics of a TCO were the films deposited at low power with the shortest deposition time.
\end{abstract}




\section{Lista de Figuras}

Figura 1: Representação esquemática das estruturas cristalinas do ZnO: (a) sal de rocha cúbica, (b) blenda de zinco cúbica e (c) wurzita hexagonal. Esferas cinzas e pretas representam respectivamente átomos de $\mathrm{Zn}$ e $\mathrm{O}$.

. .4

Figura 2: (a) Esquema da câmara utilizada no processo de deposição onde : (1) Campânula de aço inoxidável, (2) Porta amostra, (3) alvo, (4) eletrodo, (5) Válvula gaveta, (6) Bomba turbo molecular, (7) Sistema de RF composto de malha de acoplamento e gerador de RF; (b) imagem do equipamento de RF magnetron sputtering utilizado para a deposição dos filmes de $\mathrm{ZnO}$.

Figura 3: Colisão íon-núcleo. Com o íon sendo retroespalhado. 18

Figura 4: Amostra utilizada nas medidas feita pelo interferômetro. As indicações numéricas representam onde foram tiradas as medidas, as regiões contendo $\mathrm{X}$ foram regiões onde foi não foi feita a medida.

Figura 5: Amostra com os contatos de Alumínio.

Figura 6: Equipamento utilizado para a obtenção da curva $\mathrm{CxV}$

Figura 7: Curva da capacitância pela voltagem aplicada, para uma das amostras. As retas em vermelho indicam o valor da capacitância usada no cálculo.

Figura 8: Esquema da montagem para a análise do efeito Hall.....

Figura 9: Suporte de amostra para medidas de Hall.

Figura 10: Curva de reflectância modificada em função da energia, para uma das amostras. A extrapolação da reta em vermelho ao cruzar o eixo da abcissa indica o valor do band gap ótico.

Figura 11: Espectro de RBS para o filme de $\mathrm{ZnO} / \mathrm{Si}$ .27

Figura 12: Curva da taxa de deposição pela potência. .29

Figura 13: Curva da espessura pela taxa de deposição para a potência de 200W.

Figura 14: Curva da espessura pela taxa de deposição para potência de $150 \mathrm{~W}$ 30

Figura 15: Curva da espessura pela taxa de deposição para potência de $100 \mathrm{~W}$. 30

Figura 16: Curva da espessura pela taxa de deposição para potência de 50W.

Figura 17: Gráfico da constante dielétrica em relação a espessura.

Figura 18: Curva logaritmica da corrente por tensao, para todas as amostras de $\mathrm{ZnO}$..... 
Figura 19: Gráfico da condutividade e resistividade em função da espessura... .36

Figura 20: Reflectância para amostras produzidas a 200W 37

Figura 21: Reflectância para amostras produzidas a 150W. 38

Figura 22: Reflectância para amostras produzidas a 100W 39

Figura 23: Reflectância para amostras produzidas a 50W 40

Figura 24: Relação entre os índices de refração e a espessura.. .42 


\section{Lista de Tabelas}

Tabela 1: Amostras depositadas com seus respectivos parâmetros de deposição, potência e tempo de deposição. 18

Tabela 2: Valores das porcentagens de oxigênio (O) e zinco (Zn). Junto com os seus parâmetros de deposição. 26

Tabela 3: Espessura dos filmes finos com suas respectivas taxas de deposição e as variáveis de deposição 28

Tabela 4: Medidas das constantes dos dielétricos, espessuras e variáveis de deposição das amostras de $\mathrm{ZnO}$. .32

Tabela 5: Medidas da condutividade, resistividade, resistência e espessura das amostras de ZnO e suas variáveis de deposição.

Tabela 6: Medidas da condutividade, resistividade, resistência e espessura das amostras de ZnO e suas variáveis de deposição, depositadas em modo E

Tabela 7: Valores do índice de refração, band gap e espessuras das amostras de $\mathrm{ZnO}$ e suas variáveis de deposição.

Tabela 8: Valores da figura de mérito, das resistências da folha, reflectância e potência de deposição 


\section{Lista de Abreviaturas e Siglas}

$\begin{array}{ll}\text { TCO } & \text { Transparent Conductive Oxide } \\ \mathrm{CO}_{2} & \text { Dióxido de carbono } \\ \text { OLED } & \text { Organic Light Emitting Diode } \\ \mathrm{RF} & \text { Radio Frequency } \\ \mathrm{ZnO} & \text { Óxido de zinco } \\ \mathrm{Zn} & \text { Zinco } \\ \mathrm{O} & \text { Oxigênio } \\ \mathrm{WZ} & \text { Wurtzita } \\ \mathrm{ZB} & \text { blenda de zinco } \\ \mathrm{CxV} & \text { Capacitância em função da voltagem } \\ \mathrm{RBS} & \text { Rutherford Backscattering Spectroscopy } \\ \mathrm{IxV} & \text { Corrente por Voltagem } \\ \mathrm{K}-\mathrm{M} & \text { Kubelka-Munk } \\ \text { LSI } & \text { Laboratório de Sistemas Integráveis } \\ \mathrm{DI} & \text { Água deionizada } \\ \mathrm{IBA} & \text { Ion Beam Analysis } \\ & \end{array}$




\section{Lista de Símbolos}

${ }^{\circ} \mathrm{C} \quad$ Graus Celcius

$\Omega \quad$ Ohm

$\Omega_{\mathrm{S}} \quad$ Ângulo sólido

m Metro

$\sigma_{\mathrm{e}}{ }^{\mathrm{o}} \quad$ Condutividade elétrica

$\sigma \quad$ Condutividade na forma complexa

I corrente elétrica

U Queda de tensão

$N_{e} \quad$ Quantidade de carga

$\mathrm{n}_{\mathrm{e}} \quad$ Número de elétrons por volume

e Carga do elétron

$\mu_{\mathrm{e}} \quad$ Mobilidade de portadores livres

$\rho \quad$ Resistividade

$R_{\Omega} \quad$ Resistência elétrica

$L \quad$ Comprimento da estrutura tridimensional

SQ Quadrado

$\varepsilon \quad$ Constante dielétrica

$\varepsilon_{0} \quad$ Permissividade elétrica do vácuo

$\varepsilon_{\mathrm{L}} \quad$ Constante dielétrica da rede sem transportador livre

$v_{d} \quad$ Velocidade de deriva

$E_{e l} \quad$ Campo elétrico

A Área do segmento

V Volt 
S Segundo

$\alpha \quad$ Coeficiente de absorção

$T \quad$ Transmitância óptica

$\lambda \quad$ Comprimento de onda

k’ Coeficiente de extinção

n' Índice de refração real

$<n$ ’> Ínidice de refração na forma complexa

$R \quad$ Radiação refletida

$I_{0} \quad$ Intensidade de luz incidente

$\% T$ Porcentagem de transmitância ótica

$\% \mathrm{R} \quad$ Porcenttagem da reflectancia ótica

\%A Porcentagem da Absorbância ótica

Eg Band gap

$m_{e} \quad$ Massa do elétron

$\tau \quad$ Tempo médio entre colisões

$1_{t} \quad$ Livre caminho médio

$h \quad$ Constante de Planck

d Espessura do filme

C Capacitância

P Polarização induzida

$\mathrm{E}_{\mathrm{el}}^{\mathrm{pol}}$ Campo elétrico de polarização

m Massa do portador

$\omega_{\mathrm{p}} \quad$ Frequência de plasma

eV Elétron-volt

$v_{f} \quad$ Velocidade de Fermi 
$\omega \quad$ Frequência do campo aplicado

u Velocidade dos transportadores livres

$v \quad$ Frequência de oscilação do fóton incidente

hv Energia do fóton

$\beta \quad$ Parâmentro de cauda

n Fator do modo de transição eletrônica

b Coeficiente linear

$\mathrm{Pa} \quad$ Pascal

K Fator cinemático

$\mathrm{E}_{0} \quad$ Energia antes da colisão

E1 Energia após a colisão

M Massa da partícula

Z Número atômico

S Poder de freamento

$\theta \quad$ Ângulo

$V_{D C} \quad$ Potencial negativo DC autoinduzido

" Polegada

$P_{R F} \quad$ Potência de rádio frequência

$T_{F}^{o} \quad$ Temperatura final do substrato

W Watt

(R) Marca registrada

F Faraday

N Newton

Å Ângstron

I-V Corrente-tensão 
$E_{\text {Hall }}$ Campo elétrico produzido por efeito Hall

$J_{e} \quad$ Densidade de corrente

$B \quad$ Densidade de fluxo magnético

$R_{\text {Hall }} \quad$ Coeficiente Hall

A Ampère

T Tesla

$\min \quad$ Minuto

$\% \mathrm{O}$ Porcentagem de oxigênio

$\%$ Zn Poercentagem de zinco 


\section{Sumário}

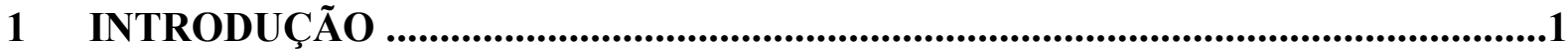

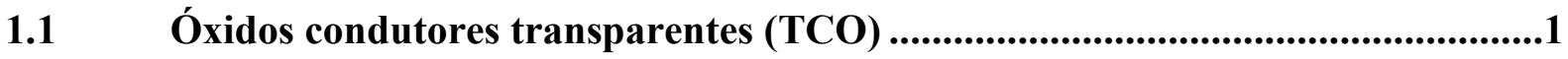

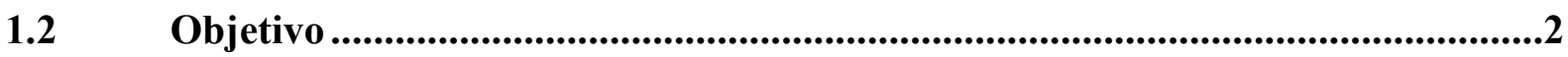

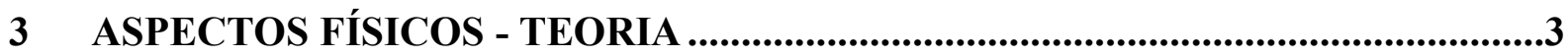

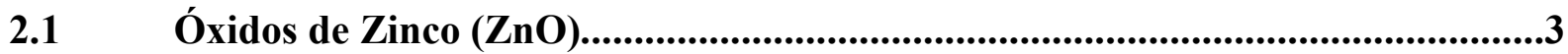

2.2 Condutividade e resistividade elétrica...........................................................4

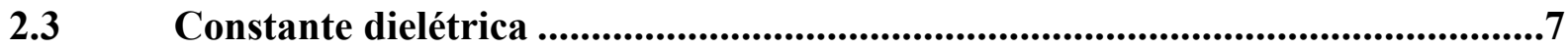

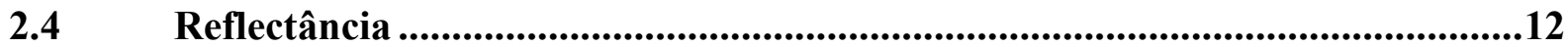

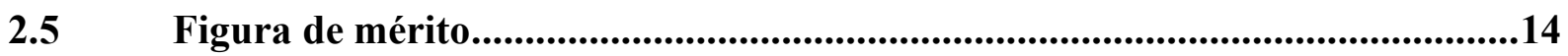

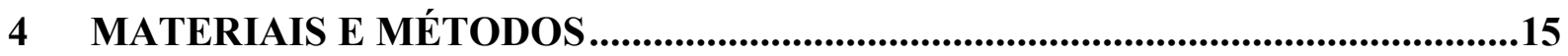

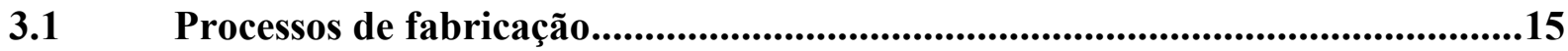

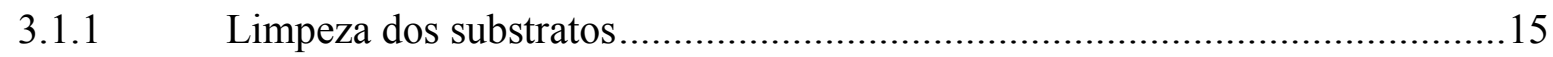

3.1.2 Deposição por magnetron sputtering via fonte radio frequência (RF)...............16

3.2 Métodos de análise ....................................................................................18

3.2.1 Rutherford Backscattering Spectrometry-(RBS) ...................................18

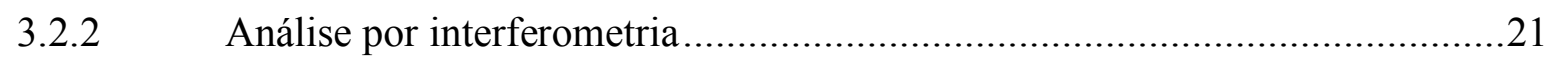

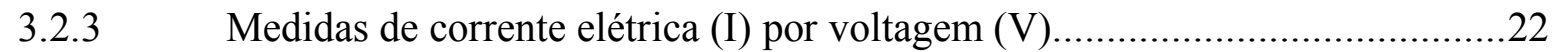

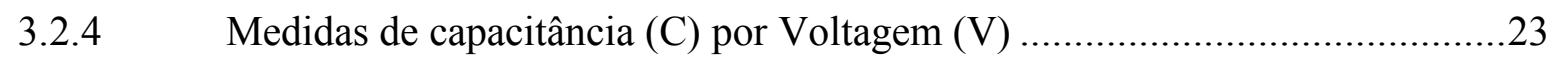

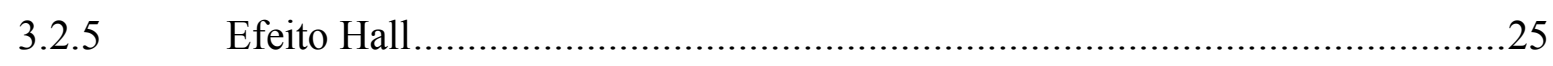

3.2.6. Espectrofotômetro - cálculo do Band gap.................................................27

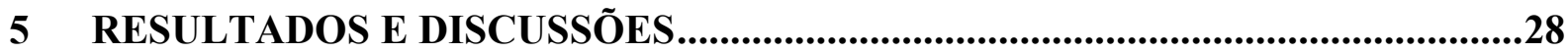

Análise por RBS ................................................................................................28

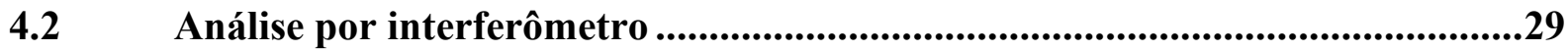

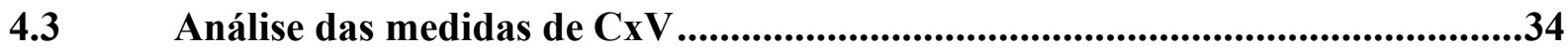

Análise das medidas de $\mathrm{IxV}$...........................................................................35

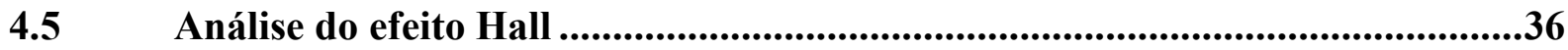

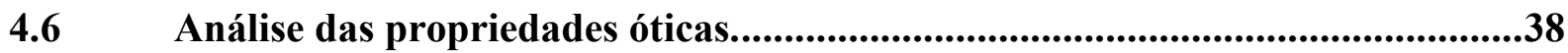

4.6.1 Análise da transparência para potência de 200W .........................................38

4.6.2 Análise da transparência para potência de $150 \mathrm{~W}$......................................40 
4.6.3 Análise da transparência para potência de 100W. .41

4.6.4 Análise da transparência para potência de 50W ........................................42

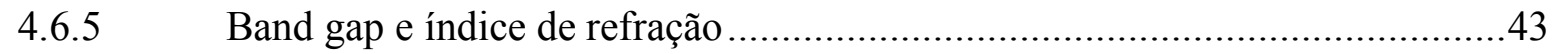

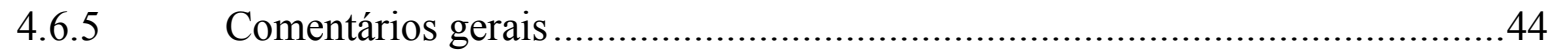

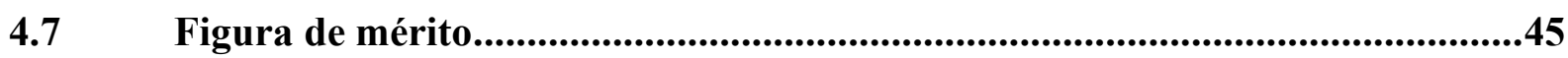

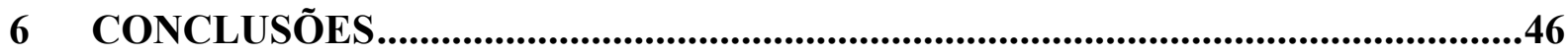

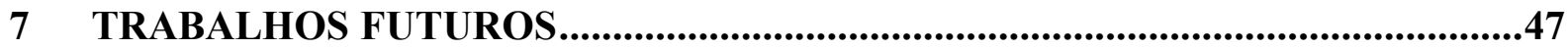




\section{Introdução}

\section{1 Óxidos condutores transparentes (TCO)}

Óxidos condutores transparentes (do inglês TCOs), são óxidos que, quando depositados na forma de filmes finos, tornam-se transparentes para os comprimentos de onda na faixa do visível e têm a capacidade de conduzir corrente elétrica, ao contrário da maioria dos materiais transparentes, que se comportam como isolantes elétricos. Os TCOs são semicondutores degenerados, ou seja, apresentam na camada de condução uma quantidade de elétrons próxima à de um metal devido à alta concentração de portadores livres do material.

Desde os primeiros resultados de filmes finos condutores e transparentes, preparados pela oxidação térmica do cádmio, produzidos por Badeker em 1907, o interesse tecnológico em condutores transparentes teve alto crescimento. Estes dispositivos de filmes finos incluem: resistores, revestimentos antiestáticos para janelas de instrumentos, revestimentos antirreflexo, componentes que absorvem a luz solar, sensores de gás, protetor e revestimentos resistentes ao desgaste para recipientes de vidro, entre outras funções ${ }^{1}$.

A partir de 1995, houve grande aumento no número de materiais TCOs. A taxa de descoberta de novos materiais aumenta a cada ano. Além disso, outros materiais foram incorporados à categoria de TCOs como filmes finos de sulfetos, nitretos, compostos de nanotubos, grafenos e polímeros em complemento aos tradicionais TCOs baseados em metais óxidos ${ }^{2}$.

Atualmente existe muito investimento para o desenvolvimento de TCOs devido ao seu papel crítico no desenvolvimento de produtos com baixo consumo de energia. Além disso, como o mundo subdesenvolvido rapidamente se torna mais tecnológico, com crescentes necessidades energéticas, o consumo total de energia resultante continuará a aumentar rapidamente. Uma consequência direta do aumento do consumo de energia é que os níveis atmosféricos de dióxido de carbono $\left(\mathrm{CO}_{2}\right)$, que são uma das principais causas do aquecimento global, estão aumentando drasticamente ${ }^{3}$. Desta forma, é vista a necessidade de uma sociedade com um estilo de vida verdadeiramente sustentável. Para isso, a sustentabilidade deve ser uma consideração em todos os aspectos de uma tecnologia, incluindo design, processamento, entrega, aplicação e, finalmente, fim de vida útil e reciclagem. Dispositivos que utilizam a energia solar, onde muitos são TCOs, têm o potencial de alterar significativamente o equilíbrio do uso de energia, permitindo novas tecnologias e melhorando a eficiência energética. Mais uma vez, isso proporciona mais motivação para mover para novos materiais TCOs, para menos 
impacto ambiental, menor custo, sustentabilidade e melhorias de eficiência em dispositivos importantes ${ }^{2}$. Desta forma podemos perceber a evolução desses dispositivos, que podem alterar as condições de consumo de energia na sociedade.

\subsection{Objetivo}

De acordo com Ravichandran et $\mathrm{al}^{4}$, para um material ser satisfatoriamente utilizado como TCO, deve obedecer aos seguintes critérios: (i) alta condutividade elétrica; (ii) alta mobilidade de portadores; (iii) alta transparência; (iv) índice de refração compatível para capturar e emitir luz; (v) facilidade de processamento; (vi) alta estabilidade; (vii) baixa toxicidade e (viii) baixo custo. Assim, este trabalho tem como objetivo caracterizar filmes de óxidos de zinco produzidos por magnetron sputtering e analisar as suas características físicas, com o enfoque na condutividade elétrica e na transparência com relação à luz visível. 


\section{Aspectos Físicos - Teoria}

Neste capítulo, serão apresentados os aspectos fisícos relacionados às propriedades dos filmes compostos de óxido de zinco.

\section{1 Óxidos de Zinco ( $\mathrm{ZnO})$}

$\mathrm{O}$ óxido de zinco (de fórmula química $\mathrm{ZnO}$ ) é um material inorgânico semicondutor do grupo II-VI. O grupo recebe essa denominação porque zinco e oxigênio, respectivamente, pertencem aos grupos 12 (II B) e 16 (VI A) da tabela periódica. Os átomos de zinco (metal) e oxigênio (não-metal) são unidos principalmente por meio de ligação iônica, resultando em íons $\mathrm{Zn}^{+2}$ e $\mathrm{O}^{-2}$, que exercem atração eletrostática entre si. Essa atração eletrostática permite a formação do retículo cristalino de $\mathrm{ZnO}$. Na natureza, o $\mathrm{ZnO}$ ocorre na forma mineral, denominada zincite 5 .

$\mathrm{O} \mathrm{ZnO}$ possui um band gap da ordem de $3.2 \mathrm{eV}$ à temperatura ambiente ${ }^{2}$, sendo um sólido pertencente à classe dos semicondutores do tipo $\mathrm{n}^{6}$. Este filme fino é um dos materiais semicondutores mais versáteis e tecnicamente interessantes devido às suas propriedades típicas $^{7}$, como o controle de resistividade na faixa de $10^{-3}$ a $10^{5} \Omega . \mathrm{cm}$. Possui alta estabilidade química e excelentes propriedades piezoelétricas ${ }^{8}$, além de apresentar transparência à luz visível, com ponto de fusão de aproximadamente $1975^{\circ} \mathrm{C}^{9}$. Outra propriedade importante é a alta abundância e baixa toxidade ${ }^{10}$.

A configuração em que os átomos irão se ordenar no substrato depende da energia que lhes é fornecida pela transferência de momento. Assim o aumento da potência rádio frequência (RF) que promove maior energia cinética aos átomos e/ou moléculas que chegam ao filme em formação, contribui para uma maior cristalização dos filmes ${ }^{11}$.

A forma mais estável do ZnO é a Wurtzita (wurtzite, ou WZ) hexagonal, porém outra forma de se solidificar é na forma cúbica, essa forma se chama blenda de zinco (zinc blende, ou ZB) ou sal de rocha (rocksalt -estrutura idêntica à do cloreto de sódio) ${ }^{12}$, como mostra a Figura 1 .

O óxido de zinco $(\mathrm{ZnO})$ é o material que tem ganhado muito destaque nos últimos anos, pois possui diversas aplicações tais como dispositivos óptico eletrônicos ${ }^{13}$, células solares ${ }^{14}$, diodos emissores de luz ${ }^{15}$ e fabricação de lasers na faixa do ultra-violeta ${ }^{16}$. 
Figura 1: Representação esquemática das estruturas cristalinas do $\mathrm{ZnO}$ : (a) sal de rocha cúbica, (b) blenda de zinco cúbica e (c) wurzita hexagonal. Esferas cinzas e pretas representam respectivamente átomos de $\mathrm{Zn}$ e O

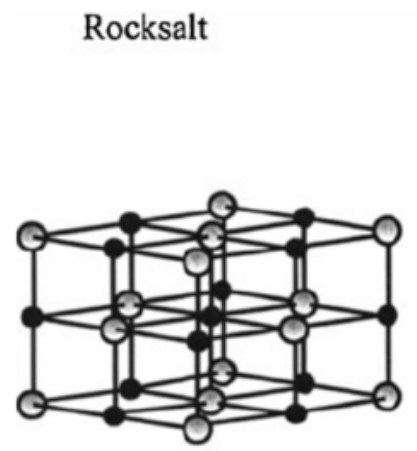

(a)

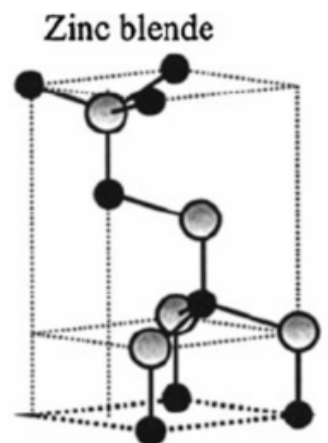

(b)

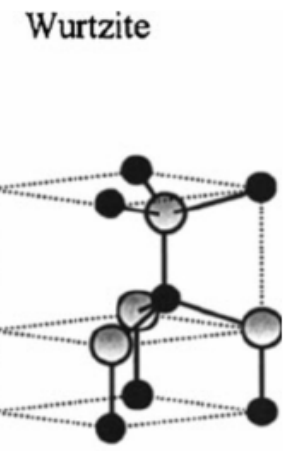

(c)

\subsection{Condutividade e resistividade elétrica}

Um parâmetro importante dos materiais TCOs é a condutividade $\sigma$. A condutividade é a habilidade de o material conduzir corrente elétrica. A seguir veremos como podemos descrever esta grandeza nos materiais semicondutores.

Considerando um metal como uma rede tridimensional regular de cátions unidos por um mar de elétrons livres para que se movam pela rede. Na ausência de um campo aplicado, o movimento é aleatório. A corrente $I$ em um segmento metálico de comprimento $L$ é definida como proporcional à queda de tensão $V$ ao longo desse segmento:

$$
I=\frac{V}{R_{\Omega}}
$$

A resistência $R_{\Omega}$ está relacionada ao comprimento $L$ e é inversamente proporcional à área da seção transversal A, da seguinte forma:

$$
R=\frac{\rho L}{A}
$$

onde $\rho$ é a resistividade do material.

Aplicando um campo Elétrico uniforme $E_{e l}$ : 


$$
E_{e l}=\frac{V}{L}
$$

e utilizando a eq. (2.2) e a eq. (2.3), podemos escrever a corrente em função do campo elétrico e da resistividade, da seguinte forma:

$$
I=\frac{E_{e l} A}{\rho}
$$

Sabendo que a corrente em um segmento está relacionada ao número de elétrons por unidade de volume $n_{e}$, a velocidade de deriva $v_{d}$ (velocidade média do elétron devido ao campo elétrico), a carga do elétron $e$, e a área do segmento $A$, então podemos escrecer a corrente da seguinte forma:

$$
I=n_{e} e A v_{d}
$$

Portanto utilizando a eq. (2.4) podemos escrever a resistividade como:

$$
\rho=\frac{E_{e l}}{n_{e} e v_{d}}
$$

Além do mais, com base na lei de Ohm, $\rho$ deve ser independente de $E_{e l}$, desta forma, a velocidade de deriva $v_{d}$ deve ser proporcional a $E_{e l}$. Na presença de um campo elétrico, um elétron livre sente uma força de magnitude $e E_{e l}$. Se essa fosse a única força, o elétron de massa $m_{e}$ teria uma aceleração ilimitada $e E_{e l} / m_{e}$. No entanto, este elétron persiste em um estado estacionário em que a velocidade de deriva é proporcional ao campo aplicado. Portanto, a colisão na rede retarda o seu movimento. Após a colisão, a velocidade não estará mais relacionada com a velocidade da deriva. Se $\tau$ é o tempo médio entre colisões, a velocidade da deriva do elétron se torna:

$$
v_{d}=\frac{e E_{e l}}{m_{e}} \tau
$$


Assim utilizando a eq. (2.6):

$$
\rho=\frac{m_{e}}{n_{e} e^{2} \tau}
$$

Sabendo que o livre caminho médio $l_{\mathrm{T}}$ é dado pela velocidade de Fermi $\mathrm{v}_{\mathrm{f}}$, e pelo tempo médio entre colisões, tem-se:

$$
l_{t}=v_{F} \tau
$$

Então, utilizando a eq.(2.8) a resistividade ficará da seguinte forma:

$$
\rho=\frac{m_{e} v_{F}}{n_{e} e^{2} l_{t}}
$$

Sabendo-se, pela lei de Ohm, que a densidade de corrente $\left(J_{e}=\sigma_{e} E_{e l}\right)$ é a quantidade de carga $N_{e}$ que passa por uma área $A$ por segundo $\tau$ é dado por:

$$
J_{e}=\frac{N_{e} e}{A \tau}
$$

Utilizando a eq. (2.9), e lembrando que $\mathrm{n}_{\mathrm{e}}$ é o número de elétrons por unidade de volume, teremos:

$$
J_{e}=n_{e} e v_{F}
$$

Sendo a condição de que a velocidade de deriva se iguale à velocidade de fermi, para um tempo um pouco antes da colisão. Utilizando a eq. (2.7) podemos escrever a densidade da corrente como:

$$
J_{e}=n_{e} \frac{e^{2} \tau}{m_{e}} E_{e l}
$$

Sabendo que $\sigma_{e}^{o}$ é a condutividade eletrônica, podendo ser expressa como densidade de corrente contínua por unidade de campo elétrico, utilizando a eq. (2.13) podemos reescrever $\sigma_{e}^{o}$ como: 
$\sigma_{e}^{o}=\frac{n_{e} e^{2} \tau}{m_{e}}$

Utilizando a equação acima, podemos definir a mobilidade de carga $\mu_{\mathrm{e}}$ como:

$$
\mu_{e}=\frac{e \tau}{m_{e}}
$$

Pode-se ver pela eq. (2.14) e eq. (2.8) que a resistividade de filmes finos é o inverso da condutividade, portanto uma forma de reduzir a resistência é aumentar a densidade de portadores ou aumentar a mobilidade eletrônica.

A mobilidade $\mu_{e}$, é limitada pela dispersão dos portadores de carga na rede. Vários mecanismos de dispersão de elétrons podem ser operacionais em TCO, como a dispersão por impurezas ionizadas, vibrações térmicas da rede (fonons acústicos e óticos), defeitos estruturais (vacâncias, deslocamentos, falhas de empilhamento) e limites de grãos, dependendo da concentração do transportador e da qualidade cristalina do materia ${ }^{17}$.

A eq. (2.14) e eq. (2.15) relacionam a condutividade com o número de portadores de carga e a sua mobilidade. Entende-se que a mobilidade generaliza todas as forças que atuam no elétron no sólido condutor. Estes, então, são considerados os parâmetros importantes a serem usados para caracterizar o transporte de carga em materiais condutores.

\subsection{Constante dielétrica}

A capacitância é a propriedade de um capacitor ou de um sistema de condutores e dielétricos permitir o armazenamento de cargas separadas eletricamente, quando existe uma diferença de potencial entre os condutores. Já o dielétrico é o meio no qual é possível produzir e manter um campo elétrico com pequeno ou nenhum suprimento de energia de fontes externas, esse campo elétrico é gerado pela própria composição dos átomos do material. A energia requerida para produzir o campo elétrico pode ser recuperada, no total ou em parte, quando o campo elétrico é removido.

A constante dielétrica $\varepsilon$ do filme fino é definida pela capacitância $C$, pela permissividade elétrica do vácuo $\varepsilon_{0}$, que é dada por $\varepsilon_{0}=8,854 \times 10^{-12} \mathrm{~F} / \mathrm{m}$ ), pela espessura do filme $d$, e pela área do capacitor $A_{c}$. Então temos: 


$$
\varepsilon=\frac{C d}{\varepsilon_{o} A_{c}}
$$

Dessa forma utilizando a eq. (2.16), e a partir da curva de capacitância em função da voltagem $(C x V)$ (que nos fornecerá o valor da capacitância), podemos descobrir qual é a constante dielétrica do filme, e assim, analisar se o material terá condições de ser um bom condutor.

Podemos relacionar a constante dielétrica do material com outras características elétricas, como a condutividade, se entendermos o mecanismo de polarização que as cargas sofrem, através das interações das ondas eletromagnéticas que chegam no material.

Considere um portador livre de massa $m$ fracamente ligado à uma rede por uma força de restauração. Se o campo aplicado oscilar em alta frequência, de modo que a inércia da massa do portador livre impeça o movimento, não haverá acoplamento no campo, portanto a transmissão será alta. No entanto, se a carga responder livremente ao campo, haverá absorção. Um simples formalismo do oscilador harmônico pode ser usado para modelar essa interação.

Os portadores são deslocados uma distância média, $x$, da posição de equilíbrio resultando em uma polarização induzida $P$.

$$
P=n_{e} e x
$$

onde $n_{e}$ é a densidade de cargas livres, e $e$ é a carga do elétron.

O campo elétrico de polarização $E_{e l}^{p o l}$ é o valor da polarização dividida pela constante dielétrica do meio:

$$
E_{e l}^{p o l}=\frac{P}{\varepsilon}
$$

Uma vez que a força é a carga multiplicada pelo campo, a equação de movimento para o operador livre, com uma força de restauração negativa, pode ser escrita como:

$$
\frac{m d^{2} x}{d t^{2}}=-\frac{n_{e} e^{2}}{\varepsilon}
$$


Então a equação de movimento terá uma solução oscilatória da forma:

$x=A \exp i\left(\frac{n_{e} e^{2} x}{m \varepsilon}\right) t$

Onde a frequência de plasma é dada por:

$\omega_{p}=\left(\frac{n_{e} e^{2}}{m \varepsilon}\right)^{\frac{1}{2}}$

Utilizando a eq. (2.15), podemos escrever a frequência de plasma como:

$\omega_{p}^{2}=\frac{n_{e} e \mu_{e}}{\varepsilon \tau}$

A condutividade está relacionada à frequência do plasma. O movimento das cargas livres é impedido devido a colisões com a rede e os defeitos estruturais, por isso devemos introduzir um termo de amortecimento na equação do movimento. Essas forças "friccionais" são proporcionais à velocidade $u$ e massa $m$, e são inversamente proporcionais ao tempo entre as colisões $\tau$. Sob a influência de um campo elétrico oscilatório, teremos:

$$
m \frac{d u}{d t}+\frac{m u}{\tau}=-e E_{e l}^{p o l}=-e C \exp (i \omega t)
$$

onde $\omega$ é a frequência do campo aplicado e C é a amplitude do campo elétrico. Uma solução de estado estacionário para a velocidade é:

$$
u(t)=\frac{e \tau E_{e l}^{p o l}(t)}{m(1+i \omega t)}
$$

Uma vez que a condutividade $\sigma$ é definida como a densidade de corrente $\left(J=n_{e} e v_{F}\right)$ por unidade de campo elétrico e aproximando a velocidade do portador de carga $u$ a velocidade de fermi $v_{F}$, teremos: 


$$
\sigma=\frac{e^{2} n_{e} \tau}{m(1+i \omega t)}=\sigma_{e}^{o}\left(\frac{1}{1+\omega^{2} t^{2}}\right)+i \sigma_{e}^{o}\left(\frac{\omega^{2} t^{2}}{1+\omega^{2} t^{2}}\right)
$$

Outra grandeza importante associada à incidência da onda no material é o índice de refração na forma complexa $<n^{\prime}>$ dada por:

$$
<n^{\prime}>=n^{\prime}+i k^{\prime}
$$

onde $n^{\prime}$ é a parte real e $k^{\prime}$ o coeficiente de extinção, parte com perdas da refração.

O índice de refração descreve a facilidade com que um raio de luz passa de um meio para o outro, sendo que quanto maior é o índice de refração do segundo meio, maior é a dificuldade na passagem da luz, devido à diminuição de sua velocidade.

A partir das equações de Maxwell, a propagação de uma onda através de um sólido depende da constante dielétrica $\varepsilon$, que define a magnitude das correntes de deslocamento devido à variação no tempo do campo aplicado, e a condutividade $\sigma$, que é uma medida da corrente real no material que é criado pelo campo elétrico. Assim sendo:

$$
<n^{\prime}>^{2}=\left(n^{\prime}+i k^{\prime}\right)^{2}=\frac{\varepsilon_{L}}{\varepsilon_{o}}-\frac{i \sigma}{\omega \varepsilon_{o}}
$$

onde $\varepsilon_{L}$ é a contribuição da rede para a constante dielétrica do material (um número que representa a constante dielétrica da rede perfeita sem qualquer transportador livre) e $\varepsilon_{0}$ é a constante dielétrica ou a permitividade elétrica do vácuo. Reescrevendo a equação de condutividade em termos da constante dielétrica complexa teremos:

$$
\varepsilon_{o}=\varepsilon^{\prime}+i \varepsilon^{\prime \prime}
$$

Analisando a equação (2.25) em relação a parte real e imaginária, e utilizando a eq. (2.27) e eq. (2.28), teremos:

$$
\varepsilon^{\prime}=n^{\prime 2}+k^{\prime 2}=\frac{\varepsilon_{L}}{\varepsilon_{o}}-\frac{\sigma_{e}^{o}}{\omega \varepsilon_{o}}\left(\frac{\omega^{2} t^{2}}{1+\omega^{2} t^{2}}\right)
$$

Utilizando a frequência de plasma da eq.(2.21), teremos:

$$
\varepsilon^{\prime}=\frac{\varepsilon_{L}}{\varepsilon_{o}}\left(1-\frac{\omega_{p}^{2}}{\omega^{2}+t^{-2}}\right)
$$


Analogamente teremos para $\varepsilon^{\prime \prime}:$

$$
\varepsilon^{\prime \prime}=\frac{\varepsilon_{L}}{\omega \tau \varepsilon_{o}}\left(\frac{\omega_{p}^{2}}{\omega^{2}+\omega^{-2}}\right)
$$

Essas equações, portanto, relacionam as propriedades óticas de um material com as propriedades elétricas através da condutividade, da constante dielétrica e do índice de refração. Estas propriedades podem ser usadas para explorar como a reflectância de um material varia com os parâmetros fundamentais que aparecem nas equações acima, pode-se ver isto através da eq. (2.32). Não faz parte do escopo desta dissertação conduzir as equações acima como um guia fenomenológico, e sim, trazer para perto como as características óticas e elétricas estão interligadas.

$$
R=\frac{(n-1)^{2}}{(n+1)^{2}}
$$




\subsection{Reflectância}

A onda eletromagnética ao atingir a amostra, pode sofrer três fenômenos distintos: reflexão, transmissão ou absorção. A reflexão $(\% R)$ é o processo onde a onda após incidir com a superfície do filme retorna para o meio de onde veio. A transmissão $(\% T)$ está relacionada com a passagem da radiação através da superfície atravessando o corpo da amostra. A absorção $(\% A)$ ocorre quando o filme absorve a radiação, transformando a energia da onda em energia térmica. Podemos ver esse processo através da eq. $(2.33)^{18}$

$$
\% R+\% T+\% A=100 \%=I_{o}
$$

onde $I_{0}$ é quantidade total de energia incidindo sobre a amostra.

Em muitos casos, a espessura das camadas do filme, aumenta proporcionalmente à absorção do material, diminuindo assim sua transmitância. Isto é atribuído ao espalhamento ótico causado por caminhos óticos mais longos ${ }^{19}$

Outra grandeza importante determinada a partir da curva de Reflectância é o band gap, onde foi utilizado o Método de Tauc $^{20}$, para a sua determinação. Jan Tauc determinou que o espectro de absorção ótica do germânio amorfo se assemelha ao espectro das transições indiretas no germânio cristalino e propôs uma extrapolação para encontrar o band gap destes estados cristalinos. Tipicamente, um gráfico de Tauc mostra a quantidade hv (a energia da luz) na abcissa e a quantidade $(\alpha h v)^{1 / n}$ na ordenada, onde $\alpha$ é o coeficiente de absorção do material. $\mathrm{O}$ valor do expoente $\mathrm{n}$ indica a natureza da transição. Este método pode ser expresso pela equação (2.34):

$$
\alpha(h v)^{\frac{1}{n}}=\beta\left(h v-E_{g}\right)
$$

onde $E_{g}$ é o band gap, hu a energia do fóton incidente, $\beta$ é a constante relacionada com a absorção da onda pelo material, chamada de "parâmetro de cauda", e $n$ sendo o fator do modo de transição. Esta grandeza depende da natureza do material, não importando se ele é cristalino ou amorfo. Para uma transição permitida indireta foi utilizado $n=2$, outros valores para $n$ são, $n=3 / 2$ para transições proibidas diretas, e $n=1 / 2$ para transições direta permitida.

Para determinar o valor de $E_{g}$ devemos plotar a curva de $\alpha(h v)^{1 / 2}$ em função da energia do fóton (hu). $\mathrm{O}$ valor de $E_{g}$ foi obtido extrapolando uma reta nesta curva, com a inclinação para $\alpha(h \cup)^{1 / 2}=0$, na região de energia do UV-Vis. Assim teremos: 


$$
E_{g}=-\frac{m}{b}
$$

onde $m$ e $b$, são o coeficiente angular e coeficiente linear respectivamente, da reta $\mathrm{y}=\mathrm{mx}+\mathrm{b}$.

$\mathrm{Na}$ maioria dos casos o coeficiente de absorção é associado à curva de transmitância. Porém, neste trabalho, a curva medida foi de reflectância. Neste caso deve-se realizar uma modificação, utilizando o método de Kubelka-Munk ${ }^{21}(\mathrm{~K}-\mathrm{M}$ ou F(R)). O método K-M é baseado na equação seguinte:

$$
F(R)=\frac{(R-1)^{2}}{2 R}
$$

onde $R$ é a reflectância, $F(R)$ é proporcional ao coeficiente de absorção $\alpha$.

Uma função de $K$ - $M$ modificada pode ser obtida multiplicando a função $F(R)$ por $h$. Desta forma tem-se:

$$
\alpha(h v)^{\frac{1}{2}} \approx(F(R) * h v)^{\frac{1}{2}}
$$




\subsection{Figura de mérito}

Figura de mérito $(\Phi)$ é uma expressão numérica usada para caracterizar o desempenho de materiais ou dispositivos em relação a outros do mesmo tipo. Como um TCO eficiente deve exibir alta condutividade elétrica e alta transparência na faixa da luz visível, independente da aplicação desejada, a figura de mérito é um método eficaz para medir a eficiência do dispositivo TCO. Esse método foi proposto por Haake ${ }^{22}$, e é dado pela eq. (2.38):

$$
\Phi=\frac{T^{10}}{R_{S}}
$$

onde $\mathrm{T}$ é a transmitância média na faixa do espectro visível e $\mathrm{R}_{S}$ é a resistência de folha.

$\mathrm{T}$ é elevada à décima potência para que tenha um maior equilíbrio entre a transmitância e a resistência.

Quanto maior for o valor da figura de mérito melhor a qualidade do filme, levando em conta apenas duas das principais propriedades ópticas e elétricas. Outras características como rugosidade do filme, uniformidade da espessura e nível de reflexão óptica na região do infravermelho podem influenciar na escolha do melhor filme. 


\section{Materiais e métodos}

A seguir estão apresentados os processos de fabricação dos filmes finos analisados e os métodos de análises utilizados.

\subsection{Processos de fabricação}

As amostras de $\mathrm{ZnO}$ utilizadas no desenvolvimento deste trabalho foram produzidas no sistema de magnetron sputtering do Laboratório de Sistemas Integráveis (LSI), no Departamento de Engenharia de Sistemas Eletrônicos da Escola Politécnica da Universidade de São Paulo (LSI-POLI-USP). São abordados nesta seção os processos de fabricação utilizados na obtenção dos filmes de $\mathrm{ZnO}$, incluindo a limpeza dos substratos e os parâmetros utilizados na deposição por magnetron sputtering.

\subsubsection{Limpeza dos substratos}

Os filmes de óxido de zinco foram depositados sobre lâminas de silício tipo p, orientação (100), com $75 \mathrm{~mm}$ de diâmetro, $360 \mu \mathrm{m}$ de espessura e resistividade na faixa de 1 a $10 \Omega . \mathrm{cm}$. Antes do início do processo de deposição, foi necessário fazer a limpeza das lâminas utilizadas como substrato, com o intuito de remover impurezas capazes de comprometer a qualidade dos filmes.

Para a limpeza das lâminas de silício destinadas à deposição dos filmes de $\mathrm{ZnO}$ diretamente, foi adotada a limpeza piranha, cuja sequência está descrita a seguir:

- Lavagem em água deionizada (DI) corrente (5 minutos, em temperatura ambiente);

- $4 \mathrm{H}_{2} \mathrm{SO}_{4}+1 \mathrm{H}_{2} \mathrm{O}_{2}\left(10\right.$ minutos a $\left.115^{\circ} \mathrm{C}\right)$;

- Lavagem em água DI corrente (5 minutos, em temperatura ambiente);

- $20 \mathrm{H}_{2} \mathrm{O}+1 \mathrm{HF}$ (até a lâmina sair seca da solução, em temperatura ambiente). 


\subsubsection{Deposição por magnetron sputtering via fonte radio frequência (RF)}

O equipamento utilizado para a fabricação dos filmes analisados neste trabalho, foi um magnetron sputtering inteiramente fabricado no LSI-POLI-USP.

No processo de sputtering, partículas são retiradas da superfície de um alvo (um bloco do material que se deseja depositar) por meio de um bombardeamento de íons de gás ou de uma mistura de gases (plasma). A formação do filme fino ocorre quando essas partículas lançadas encontram o substrato se agrupando e formando uma película. Na técnica de sputtering, os átomos são retirados mecanicamente da superfície do alvo, sendo que normalmente, o alvo é resfriado evitando-se qualquer efeito térmico ${ }^{23}$.

Muitos fatores influenciam na deposição do filme por sputtering. Dependendo da diferença de potencial que é aplicada no alvo, as partículas que sofrem tal processo de deposição possuem certa quantidade de energia (centenas de eV), e assim ao se chocarem com a superfície do substrato podem ficar na superfície, ou então penetrar algumas camadas atômicas. O choque dessas partículas no substrato proporciona a adesão do filme fino ao substrato, de modo que essa adesão é alta para filmes obtidos através dessa técnica ${ }^{24}$.

Outro fator importante para a deposição do filme, é a pressão do gás durante a deposição. Caso a pressão do gás seja alta ocorrerá uma redução da energia das partículas que saem do alvo, ocorrendo sucessivas colisões até atingir o substrato, pois essa alta pressão diminui o livre caminho médio das partículas. Se a pressão é baixa, as partículas colidirão com mais energia no substrato, pois terão maior livre caminho médio ${ }^{24}$.

Em sistemas de magnetron sputtering, é aplicado campos magnéticos que confinam os íons presentes no plasma ao redor do alvo, proporcionando o aumento do número de colisões entre os íons e o alvo para uma dada pressão do gás. Além disso, com o confinamento dos elétrons é possível sustentar o plasma em pressões mais baixas do gás ${ }^{25}$.

Em um equipamento de rádio frequência (RF) sputtering planar, o substrato é posicionado em uma câmara de baixa pressão entre dois eletrodos. $\mathrm{O}$ processo é iniciado em uma descarga luminescente, produzida na câmara de vácuo por uma fonte de potência RF (de freqüência $=13,56 \mathrm{MHz}$ ), sob pressão de processo controlada por fluxo de gás (geralmente argônio). Um potencial negativo DC $\left(V_{D C}\right)$ autoinduzido pelo plasma, é utilizado para direcionar os íons para a superfície do catodo, onde se encontra o alvo. O $V_{D C}$ é gerado por meio da aplicação do sinal RF nos eletrodos, que gera o plasma. O plasma atua como um retificador que produz uma tensão negativa média no menor dos dois eletrodos, onde está o alvo. O anodo, 
região onde se encontra o substrato, fica aterrado. Podemos ver a imagem da câmara e sua estrutura na Figura 2

Para a deposição dos filmes de $\mathrm{ZnO}$ deste trabalho, foi utilizado um alvo cerâmico circular da Kurt J. Lesker Company, com 99,999\% de pureza, 4" de diâmetro por 0,250" de espessura, de densidade $5,606 \mathrm{~g} / \mathrm{cm}^{3}$. Previamente a cada deposição, a câmara foi evacuada a uma pressão de fundo da ordem de $10^{-5} \mathrm{~Pa}$ (aproximadamente $5 \times 10^{-5} \mathrm{~Pa}$ ). A pressão de processo foi de 1,3 Pa, foi controlada por vazão de gás, sendo este argônio puro. Não houve aquecimento intencional do substrato. Os processos foram iniciados a uma temperatura média de $20^{\circ} \mathrm{C}$. No entanto, durante o processo, os substratos são aquecidos a, no máximo, $100^{\circ} \mathrm{C}$, sendo a temperatura diretamente proporcional à potência de rádio frequência $\left(P_{R F}\right)$ aplicada $^{26}$.

Os parâmetros que foram variados na deposição do filme $\mathrm{ZnO}$ foram: potência da radio frequência e tempo de deposição do filme.

Figura 2: (a)Esquema da câmara utilizada no processo de deposição onde : (1) Campânula de aço inoxidável, (2) Porta amostra, (3) alvo, (4) eletrodo, (5) Válvula gaveta, (6) Bomba turbo molecular, (7) Sistema de RF composto de malha de acoplamento e gerador de RF; (b) imagem do equipamento de RF magnetron sputtering utilizado para a deposição dos filmes de $\mathrm{ZnO}$.
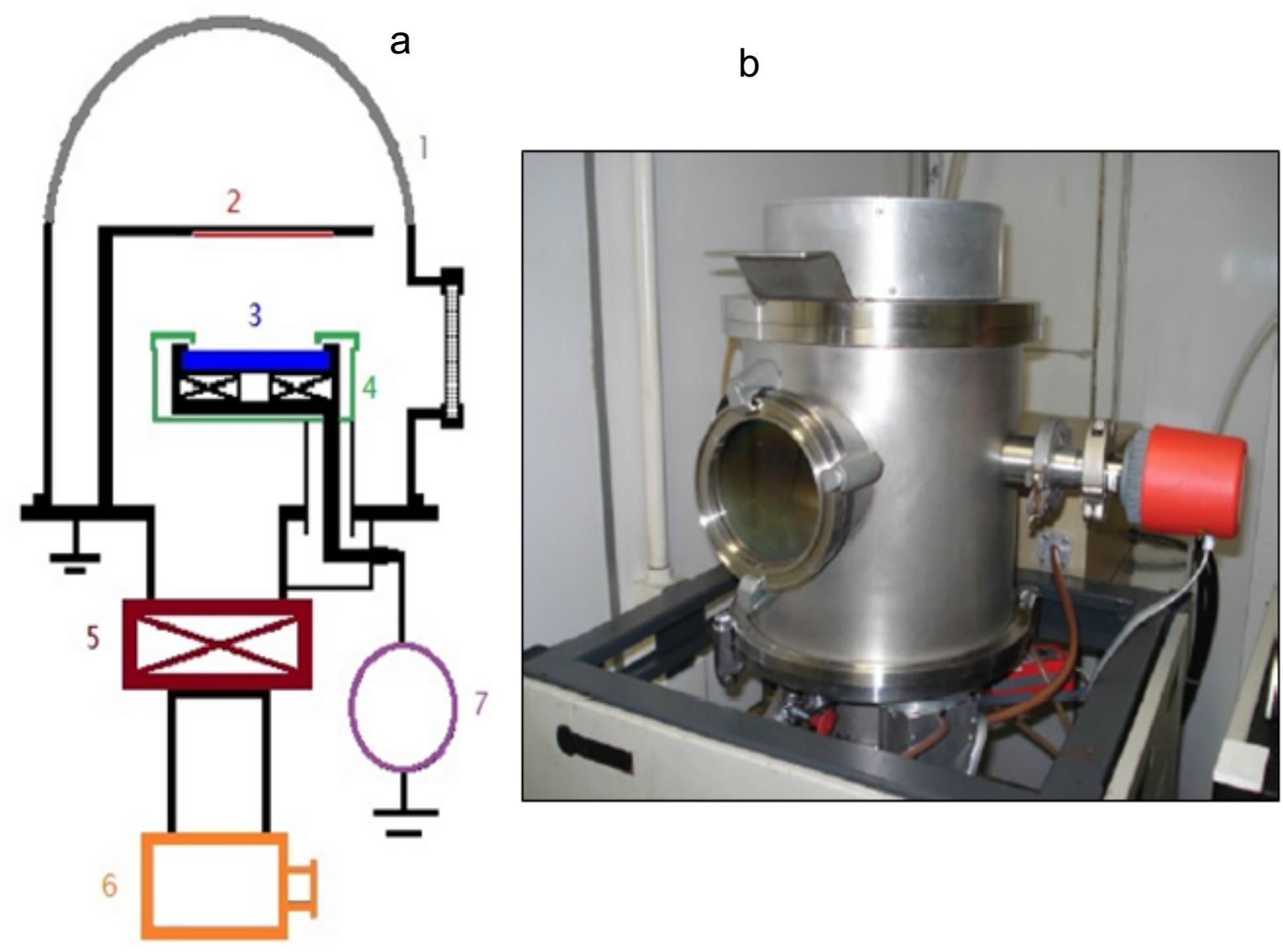


\subsection{Métodos de análise}

Nesta seção, serão descritas as técnicas experimentais utilizadas na caracterização dos filmes finos. Para esta análise foram utilizadas 12 amostras produzidas pela técnica de magnetron sputtering, com variações em função da potência RF e do tempo de deposição, tabela 1. As amostras que foram depositadas com baixa densidade de plasma, estão identificadas $\operatorname{com}(*)$.

\begin{tabular}{|c|c|c|}
\hline amostras & potência (W) & tempo de deposição (min) \\
\hline $\mathrm{K}^{*}$ & 50 & 120 \\
\hline $\mathrm{J}^{*}$ & 50 & 60 \\
\hline $\mathrm{T}$ & 50 & 15 \\
\hline $\mathrm{D}$ & 50 & 60 \\
\hline $\mathrm{I}^{*}$ & 100 & 61 \\
\hline $\mathrm{O}$ & 100 & 60 \\
\hline $\mathrm{R}$ & 100 & 15 \\
\hline $\mathrm{O}$ & 150 & 40 \\
\hline G & 150 & 60 \\
\hline M & 200 & 30 \\
\hline $\mathrm{N}$ & 200 & 15 \\
\hline $\mathrm{H}$ & 200 & 60 \\
\hline
\end{tabular}

\subsubsection{Rutherford Backscattering Spectrometry-(RBS)}

O método de análise RBS ${ }^{27}$ (Rutherford Backscattering Spectrometry) faz parte de um conjunto de métodos nuclear-espectroscópicos mais amplo denominado genericamente de métodos de análise de materiais por feixe iônico, (IBA - Ion Beam Analysis). É utilizado nesses tipos de métodos feixes de íons $\left(\mathrm{H}^{+}, \mathrm{He}^{+}, \mathrm{He}^{2+}\right.$, etc...) monoenergéticos, com energia da ordem de alguns $\mathrm{MeV}$, dezenas de nA de corrente. Esses feixes são usados para a determinação de composição elementar e perfil elementar em profundidade de filmes finos e materiais em geral. 
No retroespalhamento Rutherford, um feixe de íons de partículas monoenergéticas são direcionados a colidir com átomos de uma amostra, esses íons lancados pelo feixe, são retroespalhados e detectados por um detector que irá medir sua energia, como mostrado pela Figura 3. Na colisão, energia é transferida da partícula incidente para o átomo que está no alvo. A partir da taxa de redução da energia da partícula retroespalhada, podemos determinar a indentidade do átomo alvo, pois a redução depende da razão das massas da partícula incidente e do átomo alvo, como mostra na eq. (3.1)

$$
K=\frac{E_{1}}{E_{o}}=\left[\frac{\left.\left(M_{2}^{2}-M_{1}^{2} \sin ^{2}(\theta)\right)^{2}+M_{1} \cos (\theta)\right)}{M_{1}+M_{2}}\right]^{2}
$$

O fator cinemático $K$ é a razão entre energia do íon pós-colisão $E_{l}$ e a energia antes da colisao $E_{0}$. Em um experimento de RBS, $E_{0}, \mathrm{M}_{1}$ e $\theta$ são características conhecidas pelo experimentador, enquanto $E_{l}$ é medida pelo detector. Portanto podemos medir a massa do alvo, $M_{2}$, que representa a massa da amostra.

Após identificarmos qual é o átomo que está no alvo, podemos determinar sua densidade em átomos $/ \mathrm{cm}^{2}$ a partir da probabilidade de colisão entre as partículas incidentes e os átomos do alvo, medindo-se o número total de partículas detectadas, para um certo número de partículas incidentes, podemos determinar essa relação pela seção de choque de espalhamento.

A probabilidade de se detectar as partículas espalhadas por átomos do alvo é dada pela secção de choque diferencial definida como:

$$
\frac{d \sigma}{d \Omega}(E, \theta)=\left(\frac{Z_{1} Z_{2} e^{2}}{4 E_{o}}\right) \frac{1}{\sin ^{4}\left(\frac{\theta}{2}\right)}
$$

Onde $\sigma$ é chamado de seção de choque de Rutherford e $Z$ é o número atômico, $e$ é a carga do elétron e os índices 1 e 2 se referem ao íon e ao núcleo, respectivamente, e $\Omega_{\mathrm{S}}$ é o ângulo sólido de detecção. Ao se aproximar do núcleo, o íon começa a sentir o efeito da força elétrica e deflete na direção de um ângulo $\theta$ relativamente ${ }^{27}$ ao eixo $x$. 
Figura 3: Colisão íon-núcleo. Com o íon sendo retroespalhado

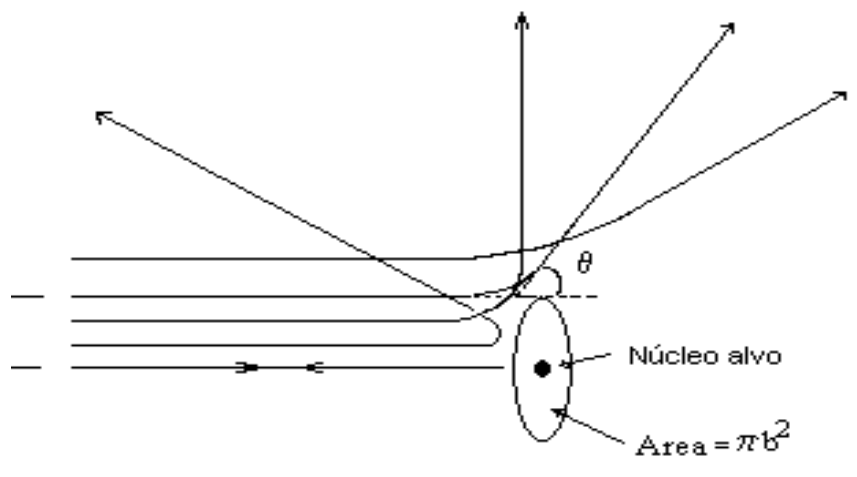

O íon ao adentrar na superfície da amostra, começa a sofrer a ação à distância da força coulombiana dos elétrons e dos núcleos do meio. Como o elétron é ordens de grandeza mais leve do que qualquer íon, colisões íon-elétron não levam o íon a desviar sua trajetória, porém essa interação faz o ion perder uma pequena parte de energia. A repetição das colisões leva o íon a gradualmente perder sua energia conforme se desloca. Portanto o íon irá perder energia enquanto se desloca dentro do material, dessa forma podemos dizer que ele perde energia por unidade de deslocamento, eq.(3.3).

$$
S(E)=-\frac{d E}{d x}
$$

onde $S$ é denominado poder de freamento.

Então a energia que o íon terá um pouco antes da colisão, não será mais sua energia inicial $E_{0}$, ela sofrerá uma redução pela taxa de freamento causado pela força Coulombiana. Sua energia pré-colisão será:

$$
E\left(x_{o}\right)=E_{o}-\int_{0}^{x_{o}} S(E) d x
$$

onde a integral no segundo termo representa o total de energia perdido até o íon alcançar a profundidade $\mathrm{x}_{0}$ quando sofrerá a colisão. Assim podemos distinguir partículas que colidiram em diferentes profundidades, dando às técnicas de $\operatorname{IBA}^{27}$ a capacidade de caracterizar não somente a composição, mas também o perfil de profundidade da composição ${ }^{28}$. 
Foram feitas medidas de todas as amostras utilizando um feixe de $\mathrm{He}^{+}$com energia de 2,2 $\mathrm{MeV}$ e um feixe de $\mathrm{He}^{2+}$ com energia de 3,06 MeV com detectores nas posições $170^{\circ}$ e $120^{0}$.

Os espectros obtidos para cada amostra foram analisados utilizando os programas SIMNRA e MultiSIMRA. A partir de informações iniciais sobre a composiçãoo e estrutura de camadas, o software MultiSIMRA aplica algoritmos para encontrar um modelo particular que se ajuste para espectros obtidos em diferentes condições experimentais (energia e geometria de detecção) de uma amostra. A simulação dos espectros é realizada pelo software SIMNRA. O procedimento de ajuste é feito otimizando a função $\mathrm{X}^{2}$, a qual está associada com as diferenças entre as frequências observadas e esperadas para um certo evento. O resultado final é obtido para o modelo que apresenta a melhor combinação possível com os dados experimentais e que minimiza a função $\mathrm{X}^{2}$ (MultiSINMRA).

\subsubsection{Análise por interferometria}

Considerando um filme fino sobre um substrato, as partes superior e inferior do filme irão refletir à luz. Devido à natureza ondulatória da luz, as reações das duas interfaces podem juntar-se de forma construtiva ou destrutiva (somando as intensidades das ondas), dependendo da relação de fase. Sua relação de fase é determinada pela diferença nos comprimentos do caminho ótico das duas ondas, que por sua vez é determinada pela espessura do filme e o comprimento de onda da luz. As reações em fase construtiva, adicionam-se quando o caminho da luz é igual a um múltiplo do comprimento de onda da luz. Para a luz perpendicular incidente sobre uma película transparente (o interfômetro foi posicionado perpendicular à amostra), temos que:

$$
2 d=i \lambda
$$

onde $d$ é a espessura da película, o fator 2 é devido ao fato de a luz passar pelo filme duas vezes, $i$ é um número inteiro e $\lambda$ é o comprimento da onda. Inversamente quando as ondas estão fora de fase e se somam de forma destrutiva o caminho da luz é metade de um comprimento de onda, ou quando $2 d=(i+1 / 2) \lambda^{29}$.

Utilizamos o interferômetro FILMETRICS F20, do Laboratório de Sistemas Integráveis, LSI, da POLI-USP para medir as espessuras dos filmes. Esta grandeza é importante para podermos caracterizar os filmes, pois utilizamos este valor para fazer o efeito Hall das 
amostras e determinar a constante dielétrica. Este equipamento também determinou o índice de refração das amostras estudadas.

Para esta análise escolhemos 4 regiões da amostra para a obtenção dos dados. Foi desconsiderada algumas regiões devido às possíveis imprecisões das medidas, pois as regiões das bordas são mais finas, Figura 4.

Figura 4: Amostra utilizada nas medidas feita pelo interferômetro. As indicações numéricas representam onde foram tiradas as medidas, as regiões contendo $\mathrm{X}$ foram regiões onde não foram realizadas medida.

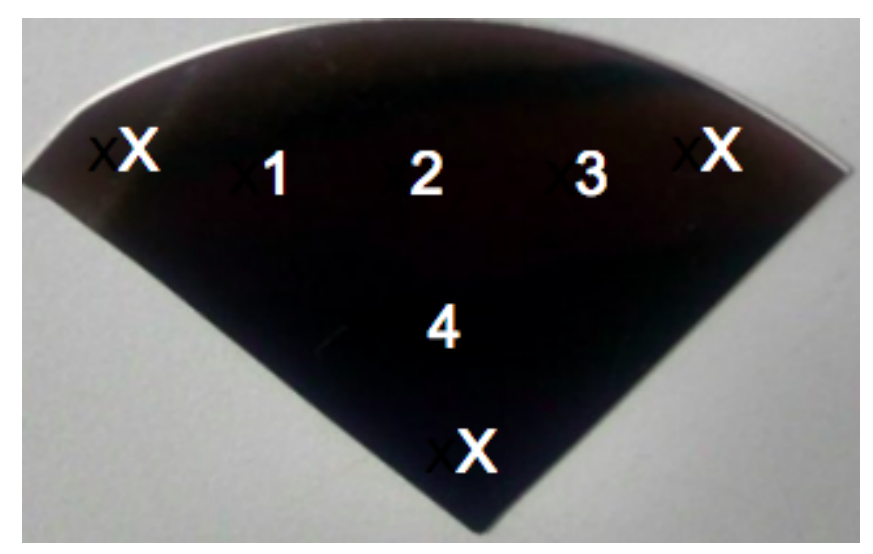

\subsubsection{Medidas de corrente elétrica (I) por voltagem (V)}

A curva de corrente elétrica em função da voltagem $(I x V)$ das amostras de $\mathrm{ZnO}$ sobre silício foi feita através de um picoamperímetro pA meter/DC 4140B, da HP no Laboratório de Sistemas Integráveis, LSI, na POLI-USP.

Foi aplicado uma tensão variando de -30 a $30 \mathrm{~V}$ na amostra através de uma ponta posicionada em cima do contato de alumínio onde se deseja aplicar a tensão (Figura 5). O procedimento utilizado foi de aplicar tensões positivas de 0 a $30 \mathrm{~V}$, e depois aplicar tensões negativas, de 0 a $-30 \mathrm{~V}$, e a partir disto, gerar uma curva de $I-V$ através da medição da corrente presente entre o ponto de contato e a base da amostra. Por característica do equipamento, as amostras continham contatos circulares de alumínio de diâmetro igual a $1 \mathrm{~mm}$ na superfície dos filmes de $\mathrm{ZnO}$. Além disso, a camada de alumínio foi depositada na superfície inferior do substrato. Assim, a resistência na ponta da lâmina seria diminuida e a área da aplicação do campo se manteria constante. 
Figura 5: Amostra com os contatos de Alumínio.

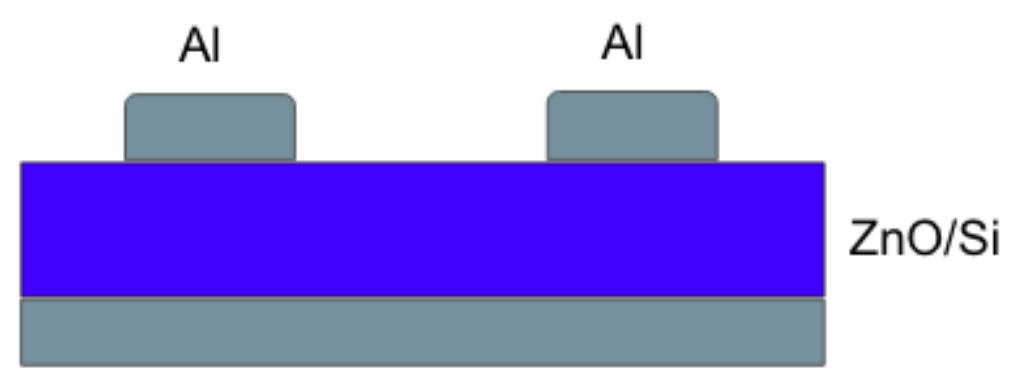

$\mathrm{Al}$

\subsubsection{Medidas de capacitância (C) por Voltagem (V)}

A curva de capacitância em função da voltage $(C x V)$ das amostras de $\mathrm{ZnO}$ sobre silício foi realizada através do equipamento HP 4280 no Laboratório de Sistemas Integráveis, LSI, na POLI-USP, Figura 6. A partir desta curva pode-se obter o valor da sua constante dielétrica $\varepsilon$.

A constante dielétrica foi encontrada utilizando a equação (2.4), onde o valor da capacitância $C$ foi encontrado fazendo a diferença do valor das capacitâncias ${ }^{30}$, para tensões positivas e tensões negativas (Figura 7). A área A neste caso será a área do contato elétrico de alumínio feito nas amostras, ver Figura 5. As capacitâncias foram encontradas pelo ajuste de retas, onde o valor do coeficiente linear representa o valor da capacitância. 
Figura 6: Equipamento utilizado para a obtenção da curva $\mathrm{CxV}$.

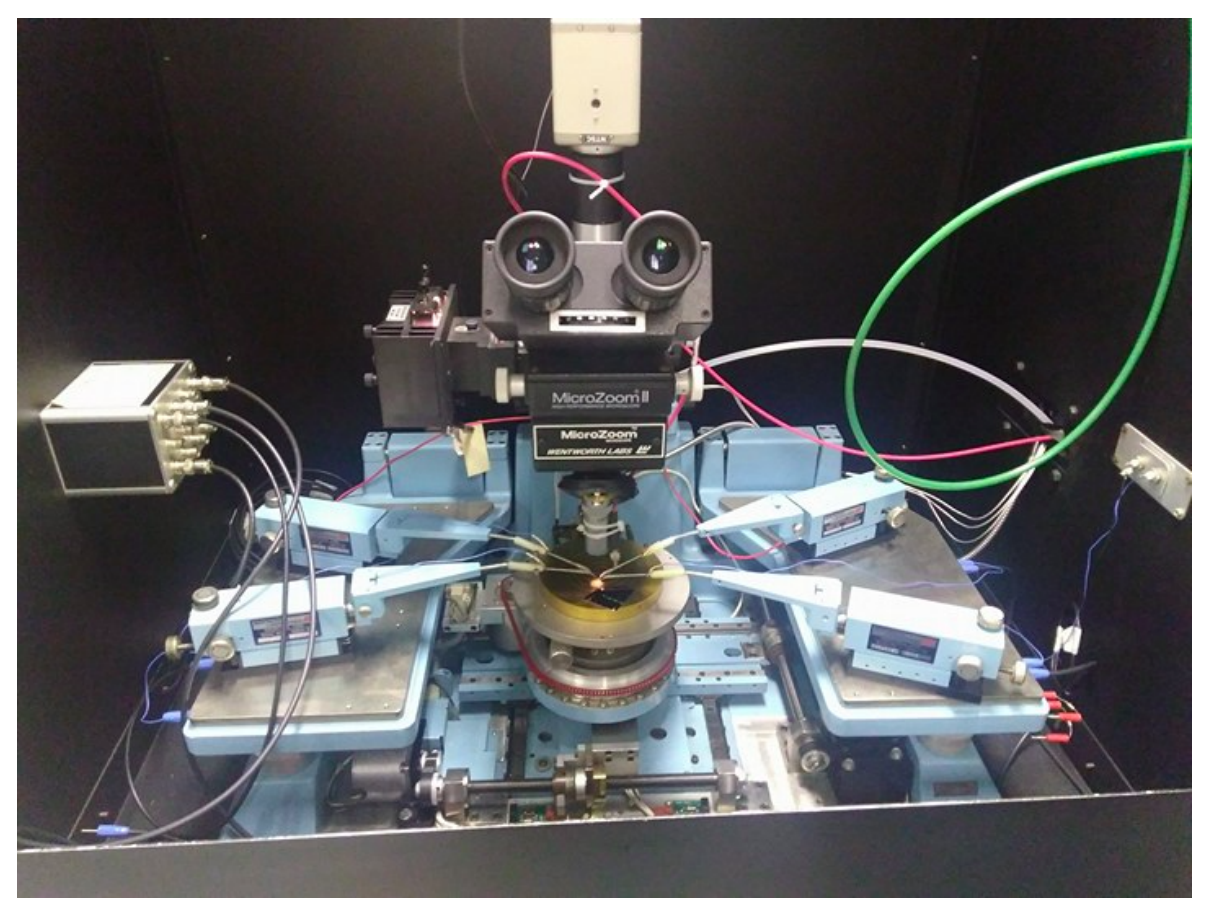

Figura 7: Curva da capacitância em função da voltagem aplicada, para uma das amostras. As retas em vermelho indicam o valor da capacitância usada no cálculo.

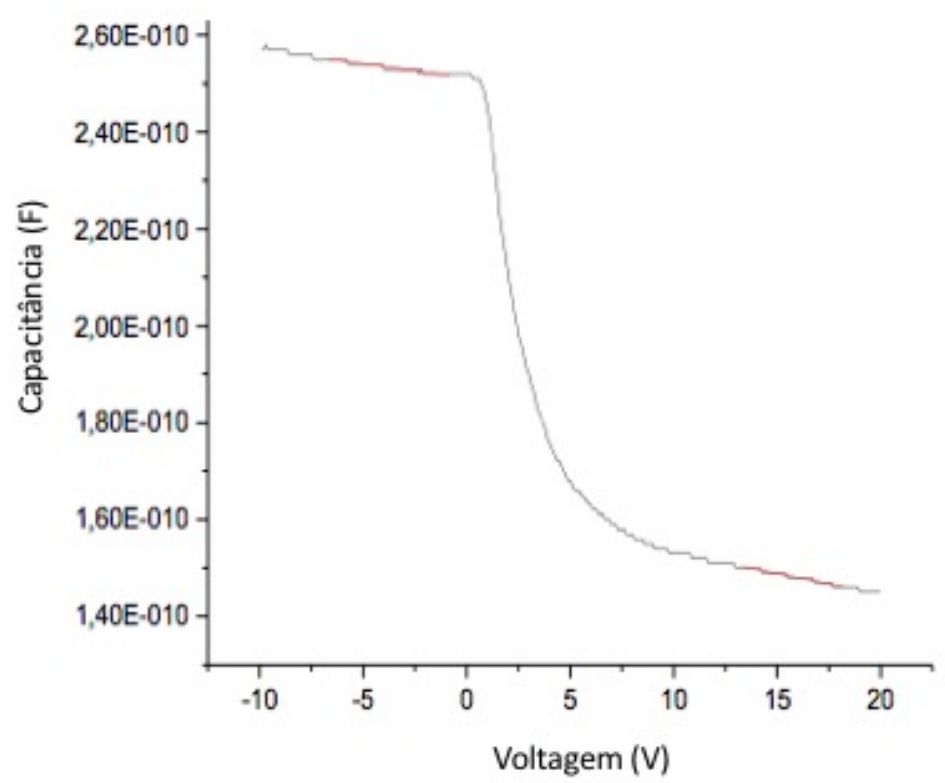




\subsubsection{Efeito Hall}

O efeito Hall pode ser observado ao aplicarmos um campo magnético $B$ na direção $z$ em uma corrente elétrica com densidade de corrente $j$ na direção $x$, através da amostra. A presença do campo fará com que elétrons experimentem uma força magnética que causará uma deflexão em sua trajetória. Essa mudança de trajetória gera um gradiente de cargas e consequentemente um campo elétrico na direção y, conhecido como campo de Hall $E_{\text {hall }}$ (3.6). O aumento de cargas nas extremidades ao longo da direção y, resulta em uma diferença de potencial conhecida como potencial de Hall, $V_{H}$.

$$
\vec{E}_{\text {Hall }}=-\vec{R}_{\text {Hall }} \vec{\jmath} \vec{B}
$$

A partir da determinação de $R_{\text {Hall, }}$ a concentração de portadores é dada pela relação descritas na eq.(3.7) .

$$
N=\frac{1}{e R_{\text {Hall }}}
$$

onde $e$ é a carga do elétron.

Esta técnica é comumente utilizada para medir resistência de folha, densidade de portadores, mobilidade de portadores e tipo de portadores. Para a realização das medidas, é necessário que quatro contatos ôhmicos sejam posicionados simetricamente em fragmentos das amostras, que também devem ter geometria simétrica para que erros de medida sejam reduzidos. Os contatos foram feitos com cola de prata e fios de cobre, de acordo com a geometria mostrada na Figura 8.

Essas grandezas serão importantes para analisarmos se as lâminas analisadas têm características elétricas semelhantes a outros TCOs. As medidas deste trabalho foram realizadas no Departamento de Engenharia de Materiais na POLI, onde o porta amostra pode ser visto na Figura 9. 
Figura 8: Esquema da montagem para a análise do efeito Hall.

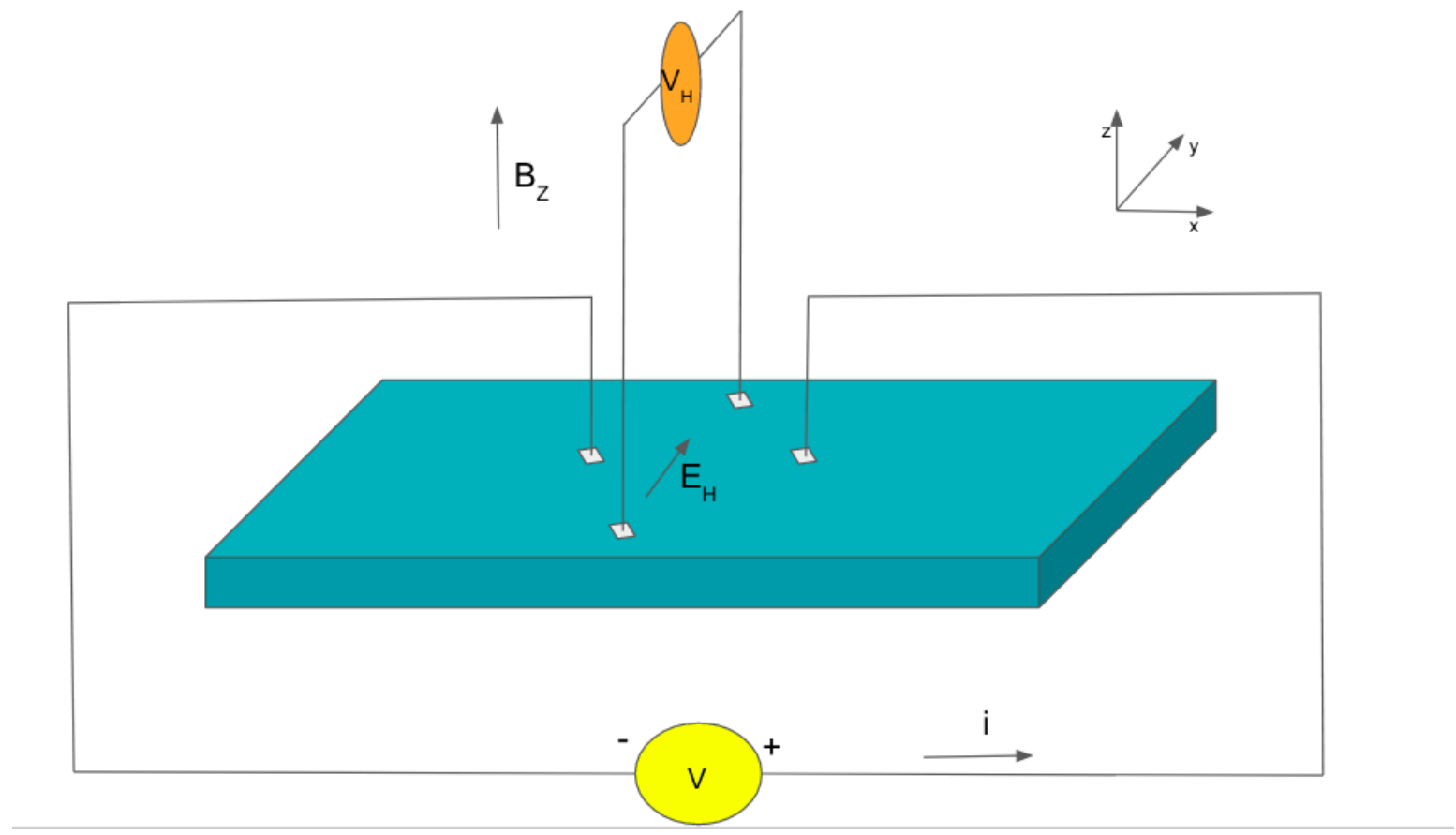

Figura 9: Suporte de amostra para medidas de Hall.

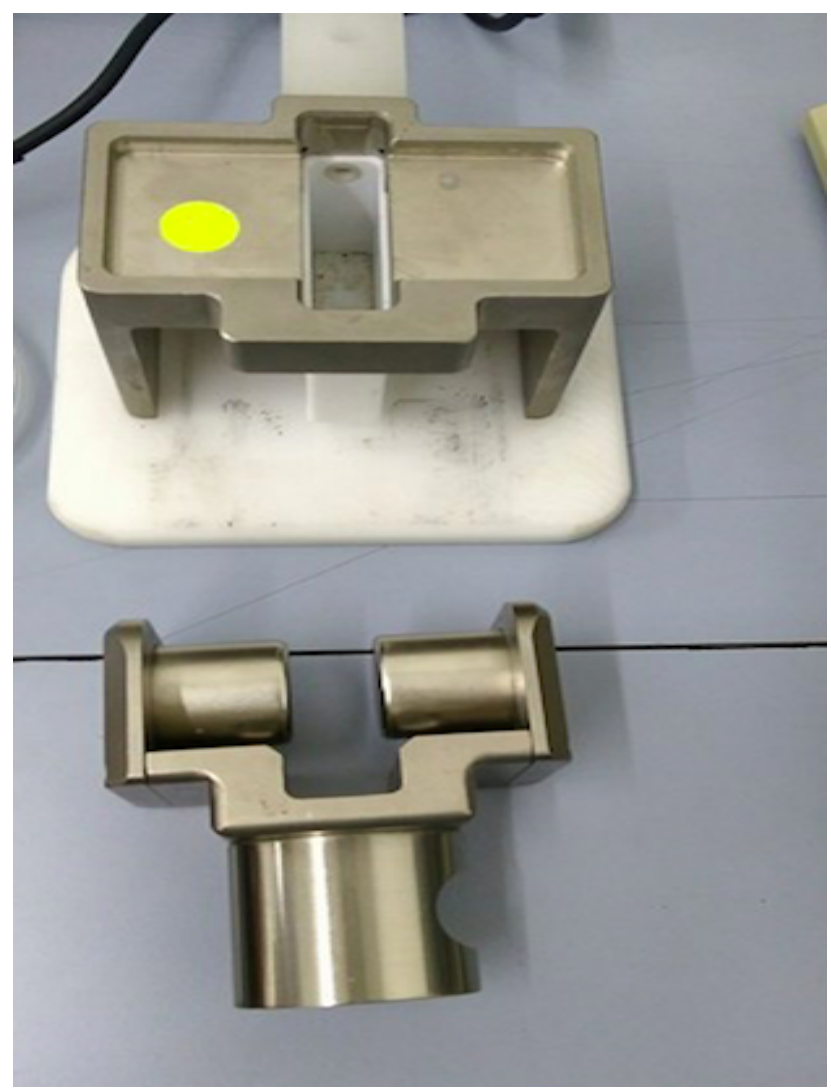




\subsubsection{Espectrofotômetro - cálculo do Band gap.}

Para analisarmos a transparência do filme, foi utilizado um espectrofotômetro CARY 7000, da Agilent pertencente ao Instituto de Física da USP (LACIFID - Laboratório de cristais iônicos filmes finos e datação). Foram obtidos os espectros de reflectância ótica dos filmes de $\mathrm{ZnO}$ em função do comprimento de onda da luz incidente. A análise será voltada para a região do espectro visível, 250 - $800 \mathrm{~nm}$.

Com a curva de $\% R$ por comprimento de onda, podemos ver como a amostra se comporta na região de comprimento de onda visível. Essa análise é importante para determinarmos se o filme é transparente. Como o substrato de Silício impede a onda de ser transmitida, a análise da reflectância se faz necessária para obtermos informações referentes à transparência da amostra, pois a onda que seria transmitida está sendo refletida. Assim quanto maior for a reflexão para um dado comprimento de onda, maior será a sua transparência

Para o cálculo do band gap foi utilizada a curva de reflectância modificada pela energia de onda incidente. Para esta curva, foi extrapolada uma reta tangente na região de energia próxima ao espectro visível, a razão entre o coeficiente angular e o coeficiente linear nos dará a energia do band gap, equação (2.35), está curva pode ser vista na Figura 10.

Figura 10: Curva de reflectância modificada em função da energia, para uma das amostras. A extrapolação da reta em vermelho ao cruzar o eixo da abcissa indica os parâmetros para se obter o valor do band gap ótico.

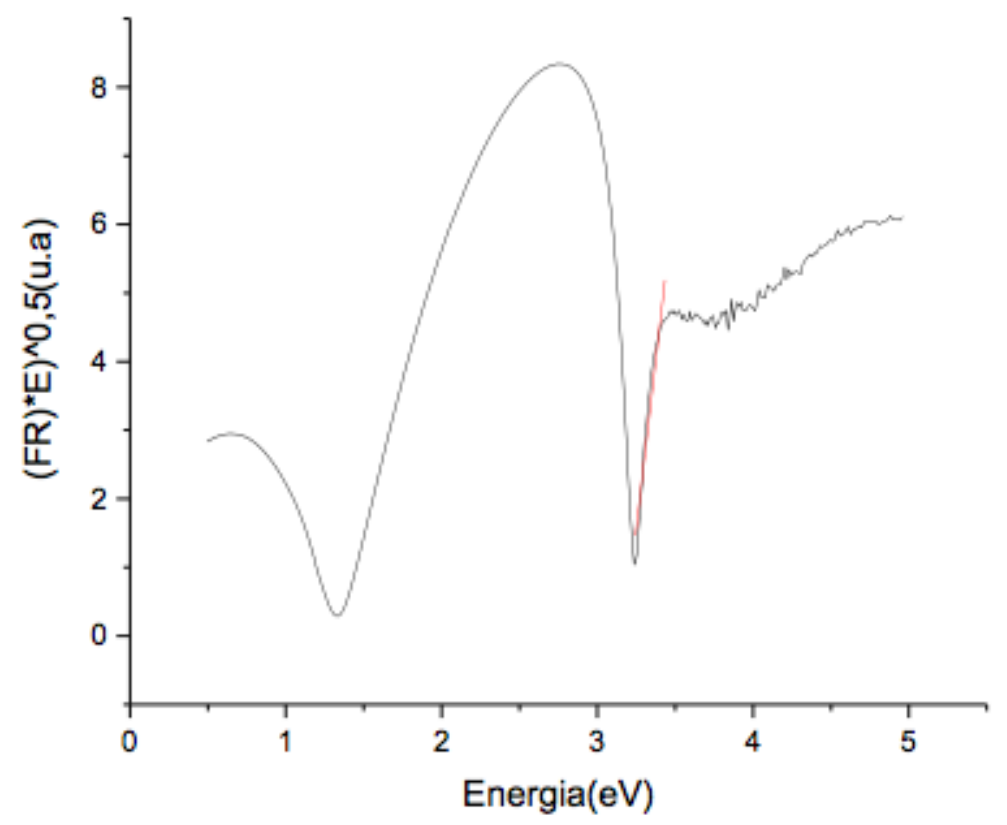




\section{Resultados e discussões}

Nesta seção discutiremos os resultados obtidos através dos métodos de análises descritos anteriormente. Os parâmetros de deposição utilizados foram a potência e o tempo de deposição. Os filmes finos foram depositados para potências de 50W, 100W, $150 \mathrm{~W}$ e $200 \mathrm{~W}$. Foi utilizada uma pressão de argônio de 1,3 Pa e os tempos de deposição variaram desde 15 min a 120 min. Algumas amostras foram depositadas com baixa densidade de plasma, que foi chamada de "modo E" de deposição. Estas amostras serão indicadas na tabela com um asterisco (*). Todas as incertezas foram calculadas pelo desvio padrão do comjunto de dados obtido nas medições.

\subsection{Análise por RBS}

Os resultados obtidos para a estequiometria do $\mathrm{ZnO}$ obtidos a partir da técnica de RBS, estão descritos na Tabela 2.

\begin{tabular}{|c|c|c|c|c|c|}
\hline potência (W) & pressão $(\mathrm{Pa})$ & deposição(min) & $\% \mathrm{O}$ & $\% \mathrm{Zn}$ & lâminas \\
\hline \multirow{4}{*}{50} & \multirow{4}{*}{1,3} & 120 & $54,6 \pm 1,1$ & $45,4 \pm 0,9$ & $\mathrm{~K}^{*}$ \\
\hline & & 60 & $55,5 \pm 1,1$ & $44,5 \pm 0,9$ & $\mathrm{~S}$ \\
\hline & & 60 & $54,9 \pm 1,1$ & $45,1 \pm 0,9$ & $\mathrm{D}$ \\
\hline & & 15 & $53,2 \pm 1,1$ & $46,8 \pm 0,9$ & $\mathrm{~T}$ \\
\hline \multirow{4}{*}{100} & \multirow{4}{*}{1,3} & 35 & $58,1 \pm 1,2$ & $41,9 \pm 0,8$ & E \\
\hline & & 61 & $54,8 \pm 1,1$ & $45,2 \pm 0,9$ & $\mathrm{I}^{*}$ \\
\hline & & 30 & $54,5 \pm 1,1$ & $45,5 \pm 0,9$ & Q \\
\hline & & 15 & $55,5 \pm 1,1$ & $44,5 \pm 0,9$ & $\mathrm{R}$ \\
\hline 150 & 1,3 & 40 & $53,6 \pm 1,1$ & $46,4 \pm 0,9$ & $\mathrm{O}$ \\
\hline 200 & 1,3 & 30 & $53,8 \pm 1,1$ & $46,2 \pm 0,9$ & $\mathrm{M}$ \\
\hline
\end{tabular}

Podemos ver na tabela 2, que os valores da porcentagem de oxigênio e de zinco estão muito próximos para todas as lâminas, mesmo que as mesmas tenham tempo de deposição e 
potência diferentes. Portanto o método de deposição por magnetron sputerring, mantém aproximadamente a estequiometria do alvo. A porcentagem de oxigênio variou de $\% \mathrm{O}=58,1 \pm 1,2$ como o valor mais alto e $\% \mathrm{O}=53,2 \pm 1,1$ como o menor valor. Consequentemente o valor mais alto de porcentagem de zinco foi de $\% \mathrm{Zn}=46,8 \pm 0,9$ e a menor $\% \mathrm{Zn}=41,9 \pm 0,8$. Tornando a razão zinco e oxigênio aproximadamente 1,1 a 1,4. A Figura 11 mostra o espectro do RBS ajustado pelo programa MultiSINMRA.

Figura 11: Espectro de RBS para o filme de $\mathrm{ZnO} / \mathrm{Si}$.

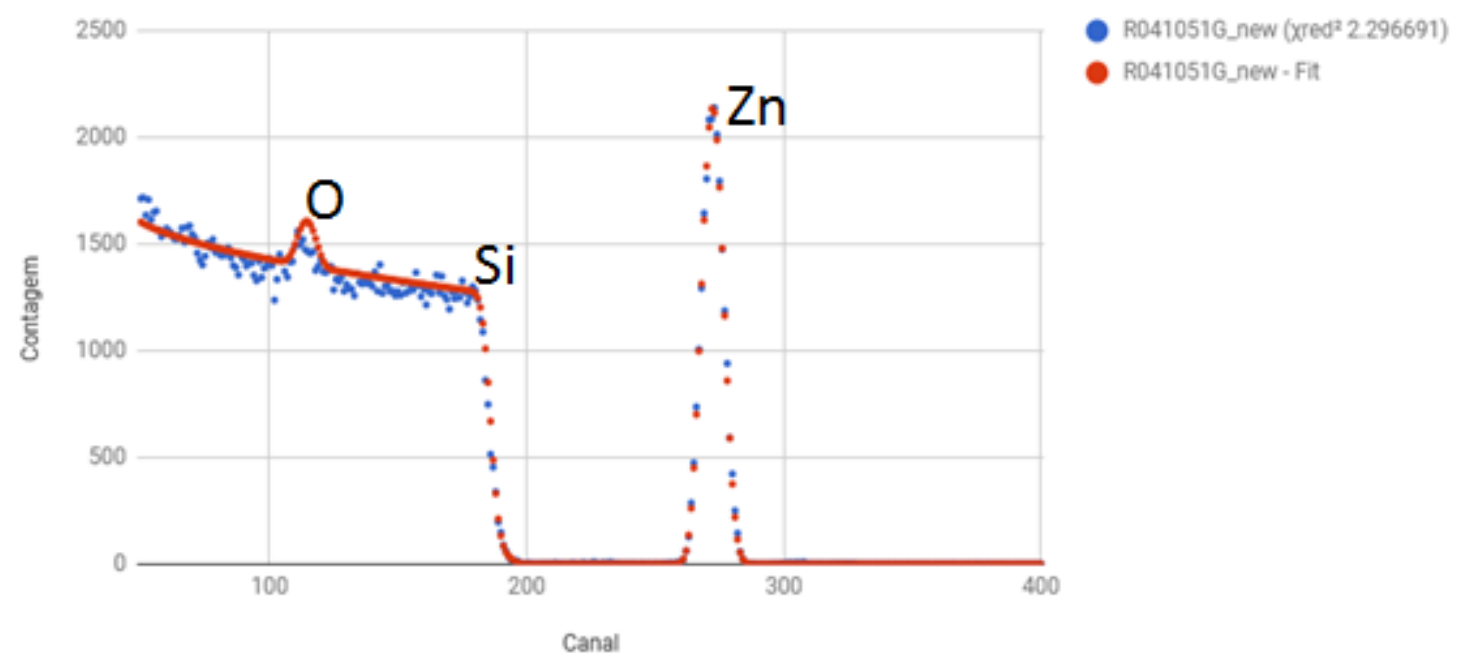

\subsection{Análise por interferômetro}

As medidas da espessura do filme de óxido de zinco pelo interferômetro foram realizadas no equipamento FILMETRICS F20. Os resultados obtidos por interferometria e os parâmetros de deposição, estão descritos na tabela 3. Foi calculado a taxa de deposição (espessura do filme dividido pelo tempo de deposição) para a análise referente à potência, isto é, para determinar a influência da potência na deposição do filme fino. 


\begin{tabular}{|c|c|c|c|c|}
\hline \multicolumn{5}{|c|}{ Tabela 3: Espessura dos filmes finos com suas respectivas taxas de deposição e as variáveis } \\
de deposição & \\
\hline potência(W) & deposição(min) & espessura(nm) & taxa de deposição(nm/min) & lâminas \\
\hline 50 & 15 & $26 \pm 1$ & $1,74 \pm 0,06$ & $\mathrm{~T}$ \\
\hline 50 & 60 & $33 \pm 3$ & $0,55 \pm 0,05$ & $\mathrm{~J}$ \\
\hline 50 & 120 & $80 \pm 3$ & $0,67 \pm 0,02$ & $\mathrm{~K}^{*}$ \\
\hline 100 & 15 & $82 \pm 4$ & $5,5 \pm 0,3$ & $\mathrm{R}$ \\
\hline 200 & 15 & $84 \pm 13$ & $5,6 \pm 0,9$ & $\mathrm{~N}$ \\
\hline 100 & 61 & $93 \pm 3$ & $1,53 \pm 0,05$ & $\mathrm{I}$ \\
\hline 50 & 60 & $152 \pm 8$ & $2,5 \pm 0,1$ & $\mathrm{D}$ \\
\hline 100 & 60 & $392 \pm 22$ & $6,5 \pm 0,4$ & $\mathrm{Q}$ \\
\hline 200 & 30 & $423 \pm 24$ & $17 \pm 1$ & $\mathrm{M}$ \\
\hline 150 & 40 & $430 \pm 20$ & $10,7 \pm 0,5$ & $\mathrm{O}$ \\
\hline 150 & 60 & $777 \pm 99$ & $12 \pm 1$ & $\mathrm{G}$ \\
\hline 200 & 60 & $1041 \pm 44$ & $14,1 \pm 0,6$ & $\mathrm{H}$ \\
\hline
\end{tabular}

Pode se observar através da tabela 3 que existe uma convergência do aumento dos valores das espessuras em relação ao aumento do tempo de deposição e ao aumento da potência. O resultado obtido se comporta de acordo com o esperado, já que durante o processo de deposição, o aumento da potência promove uma maior ionização do gás e assim, uma maior taxa de sputtering, levando a uma maior taxa de deposição, até que ocorra a saturação do sistema. Este aumento está representado na Figura 12.

As lâminas $J, K, I$ possuem taxas de deposição menores mesmo com um aumento do tempo de deposição e aumento de potencia, pois essas lâminas foram depositadas com baixa densidade de plasma, modo E. Desta forma, houve uma diminuição do bombardeamento do gás e menor pulverização do alvo. As amostras tendem a ter suas espessuras aumentadas conforme um aumento na taxa de deposição, para todas as potências. A Figura 13, Figura 14, Figura 15 e Figura 16 representam esta tendência para as potências de $200 \mathrm{~W}, 150 \mathrm{~W}, 100 \mathrm{~W}$ e $50 \mathrm{~W}$ respectivamente. 
Figura 12: Curva da taxa de deposição pela potência

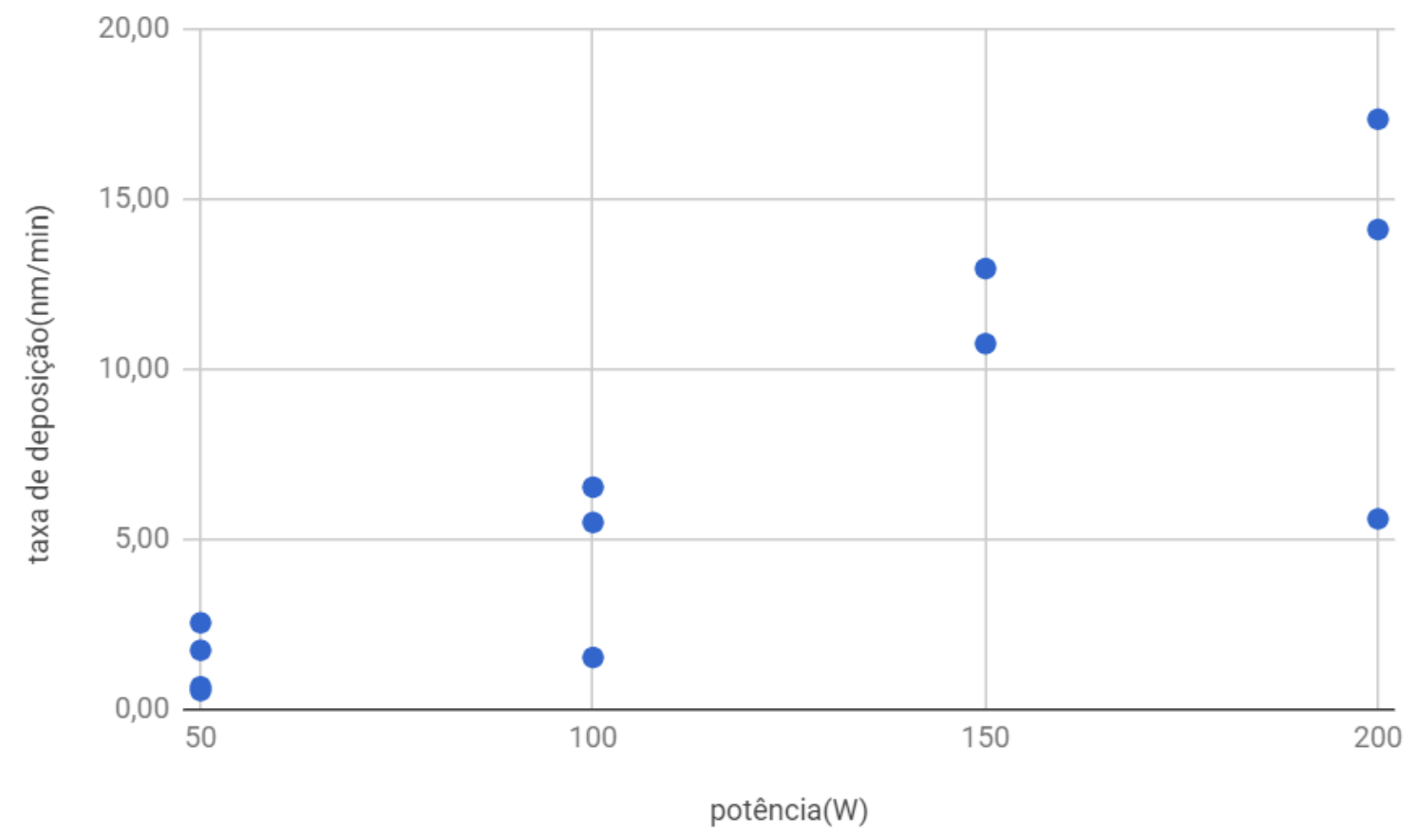

Figura 13: Curva da espessura pela taxa de deposição. para a potencia de 200W

\section{Potencia de 200W}

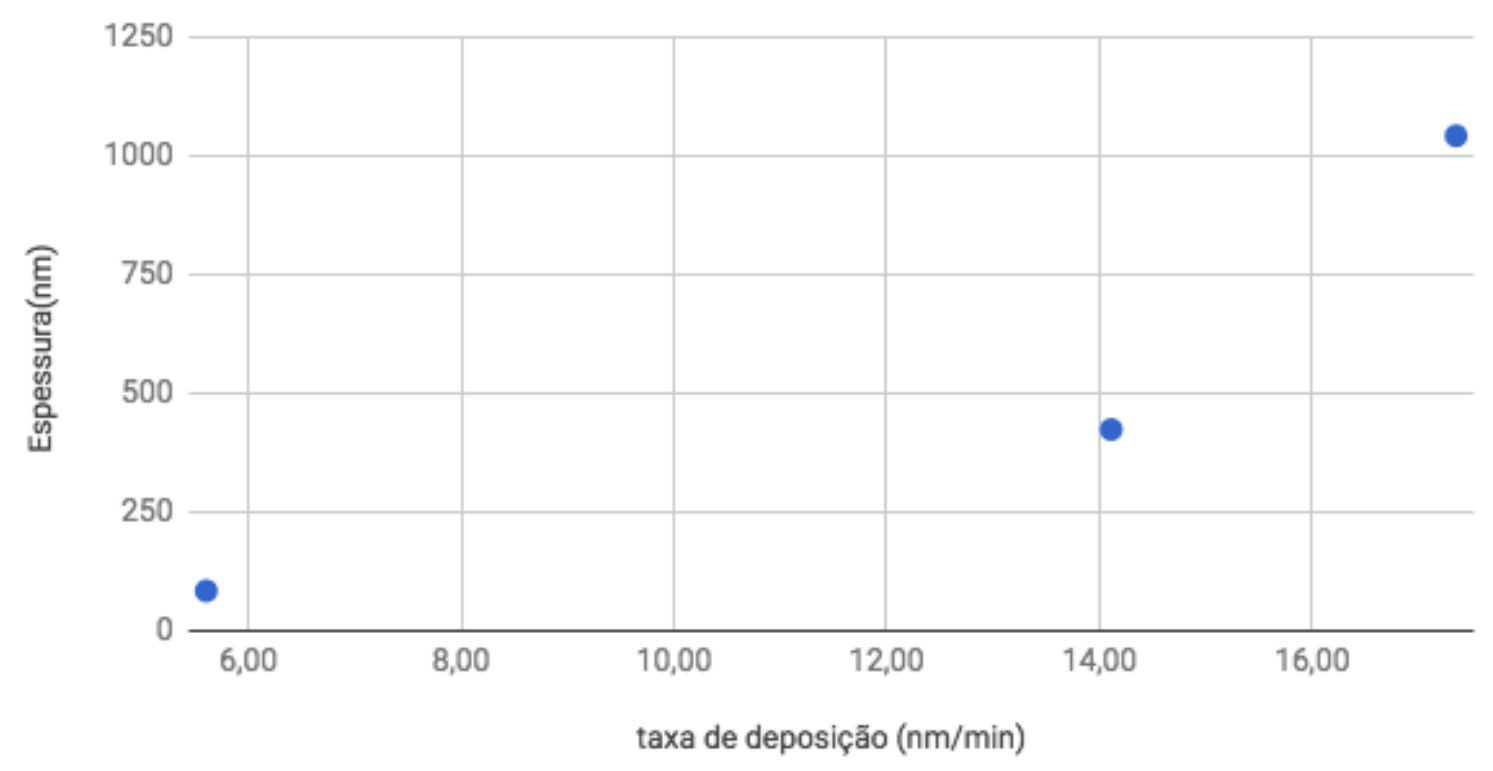


Figura 14: Curva da espessura pela taxa de deposição para potência de 150W

Potência para 150W

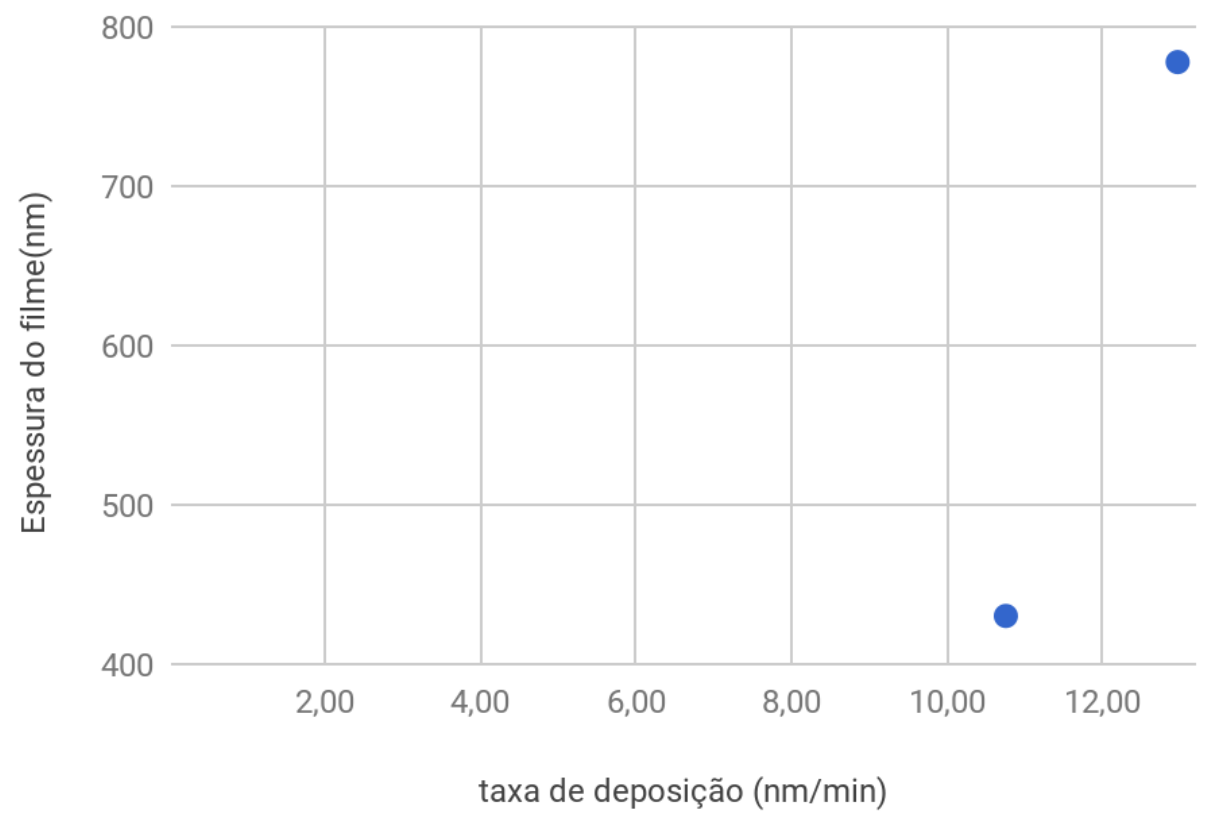

Figura 15: Curva da espessura pela taxa de deposição para potência de 100W

\section{Potência de 100W}

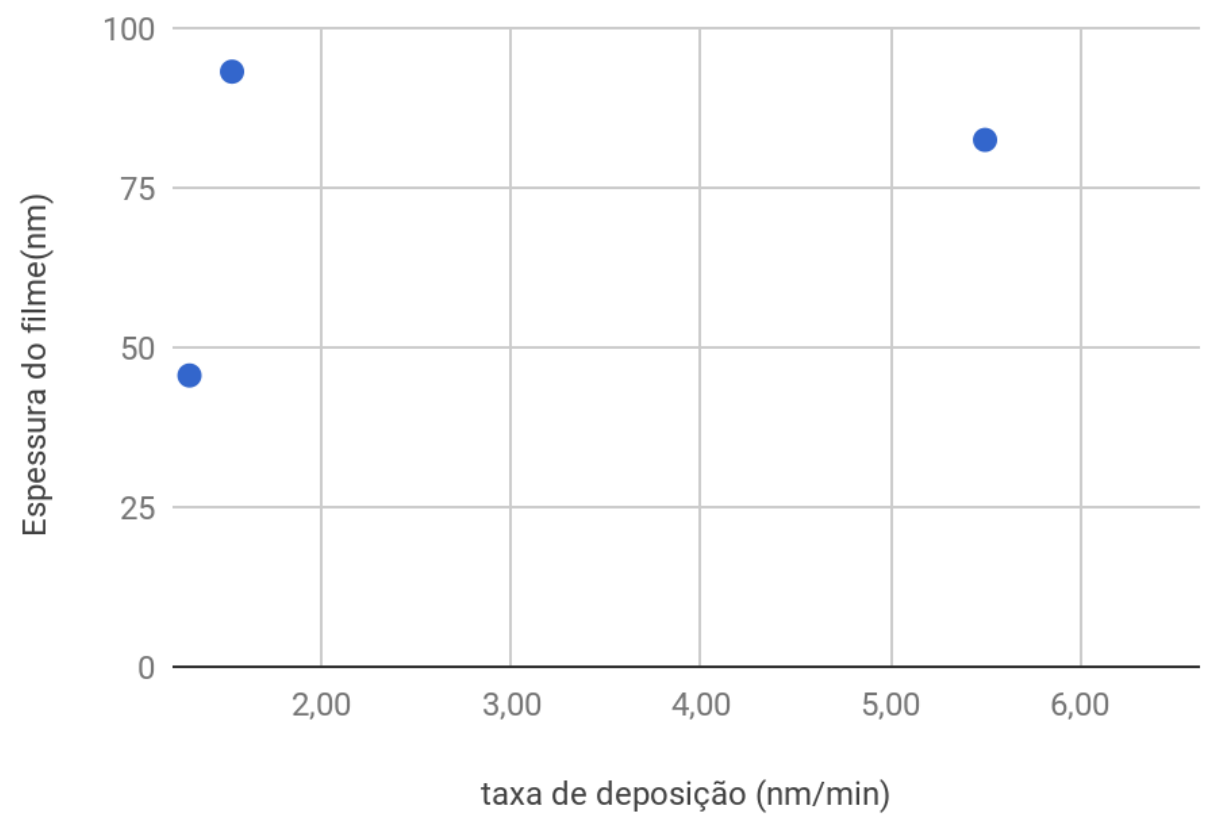


Figura 16: Curva da espessura pela taxa de deposição para potência de 50W

\section{Potencia de 50W}

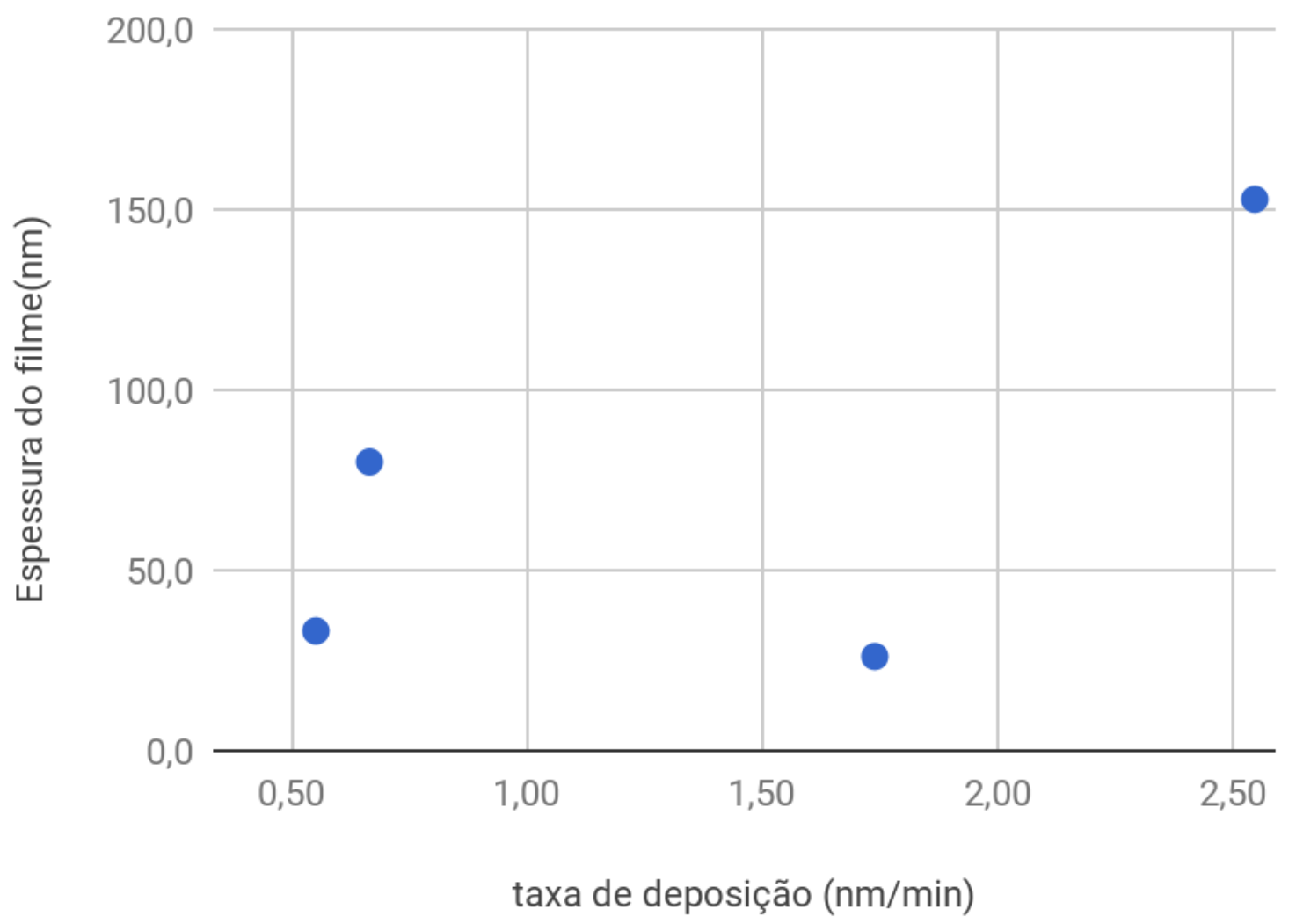




\subsection{Análise das medidas de $\mathrm{CxV}$}

As medidas de $\mathrm{CxV}$ dos filmes de óxido de zinco foram realizadas pelo equipamento HP 4280 no Laboratório de Sistemas Integráveis, LSI, da POLI-USP. Com base nesta curva e utilizando a equação (2.16), obtivemos as constantes dielétricas das amostras. Os valores assim como as variáveis de deposição e suas espessuras estão descritos na tabela 4 .

Tabela 4:Medidas das constantes dos dielétricos, espessuras e variáveis de deposição das amostras de $\mathrm{ZnO}$.

\begin{tabular}{|c|c|c|c|}
\hline potência $(\mathrm{W})$ & dielétrico $\left(\mathrm{F} / \mathrm{m}^{2}\right)$ & espessura(nm) & lâminas \\
\hline 50 & $0,21 \pm 0,03$ & $33 \pm 3$ & $\mathrm{~J}^{*}$ \\
\hline 50 & $0,36 \pm 0,03$ & $26 \pm 1$ & $\mathrm{~T}$ \\
\hline 50 & $0,69 \pm 0,05$ & $80 \pm 3$ & $\mathrm{~K}^{*}$ \\
\hline 100 & $0,78 \pm 0,07$ & $93 \pm 3$ & $\mathrm{I}^{*}$ \\
\hline 50 & $0,95 \pm 0,07$ & $152 \pm 8$ & $\mathrm{D}$ \\
\hline 100 & $1,07 \pm 0,08$ & $82 \pm 4$ & $\mathrm{R}$ \\
\hline 200 & $1,25 \pm 0,09$ & $84 \pm 13$ & $\mathrm{~N}$ \\
\hline 150 & $2,19 \pm 0,21$ & $430 \pm 20$ & $\mathrm{O}$ \\
\hline 100 & $4,11 \pm 0,29$ & $392 \pm 22$ & $\mathrm{Q}$ \\
\hline 200 & $4,12 \pm 0,29$ & $423 \pm 24$ & $\mathrm{M}$ \\
\hline 150 & $11,14 \pm 0,79$ & $777 \pm 99$ & $\mathrm{G}$ \\
\hline 200 & $14,73 \pm 1,04$ & $1041 \pm 44$ & $\mathrm{H}$ \\
\hline
\end{tabular}

A constante dielétrica das amostras de $\mathrm{ZnO}$ obtidas pela curva $\mathrm{CxV}$ e pela eq. (2.16) apresentaram uma tendência de aumentar conforme o aumento da espessura, Figura 17. Resultado esperado conforme a eq. (2.16), pois nessa equação a constante dielétrica aumenta diretamente conforme o aumento da espessura. Sendo o maior valor da constante dielétrica de $14,73 \pm 1,04 \mathrm{~F} / \mathrm{m}^{2}$ para a lâmina $H$ e o menor valor de $0,21 \pm 0,03 \mathrm{~F} / \mathrm{m}^{2}$ para a lâmina $J$. Pôde se perceber que as lâminas que foram depositadas em modo $\mathrm{E}$ lâminas: $K, J \mathrm{e} I$, obtiveram menores valores para a constante dielétrica, comparadas a outras lâminas com as mesmas características de deposição e com espessuras próximas. 
Figura 17: Gráfico da constante dielétrica em função da espessura.

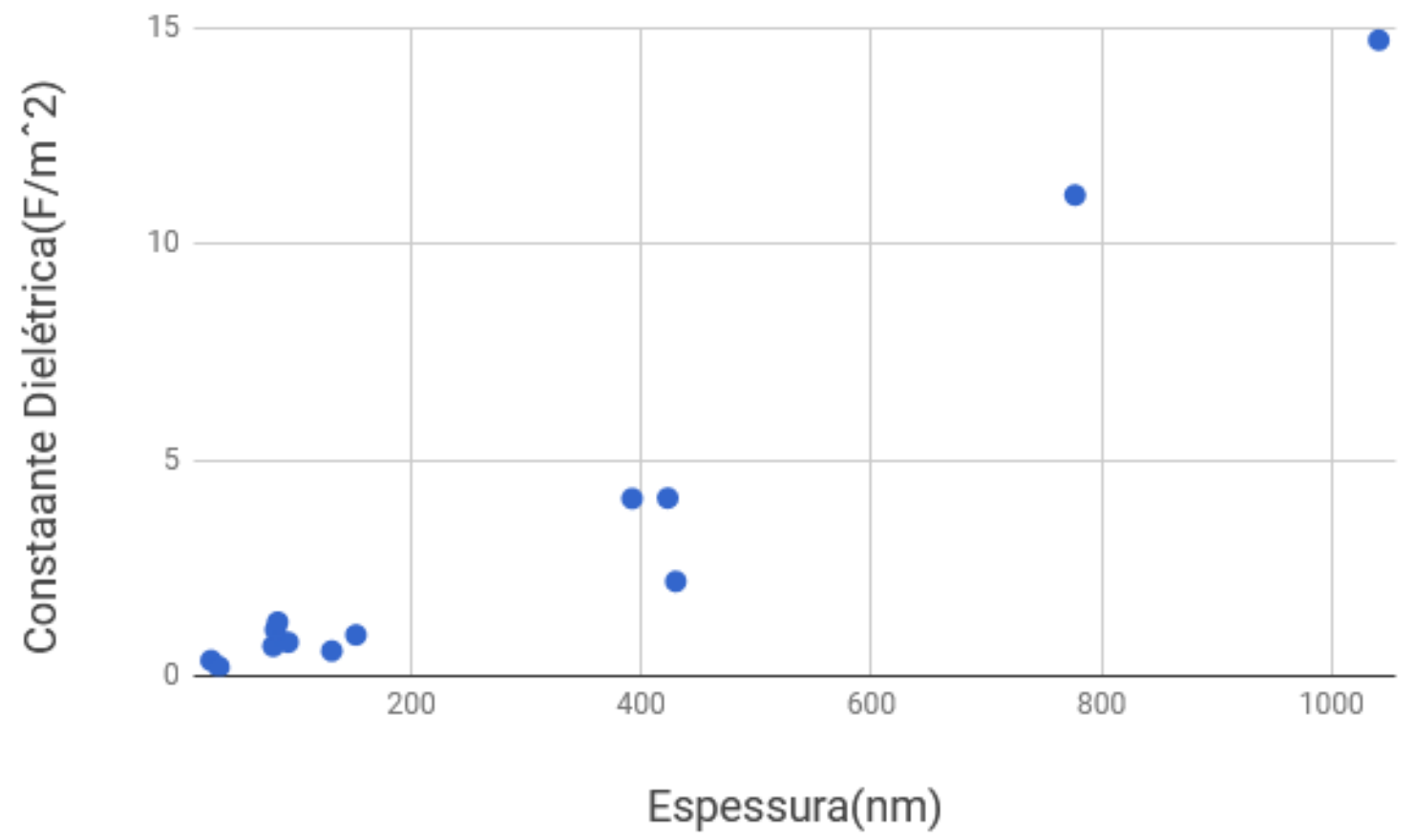

\subsection{Análise das medidas de IxV}

A curva $I x V$ das amostras de $\mathrm{ZnO}$ sobre silício foram obtidas através de um picoamperímetro pA meter/DC 4140B, da HP no Laboratório de Sistemas Integráveis, LSI, da POLI-USP. As curvas para todas as amostras estão na Figura 18.

Figura 18: Curva logaritmica da corrente por tensão, para todas as amostras de $\mathrm{ZnO}$.

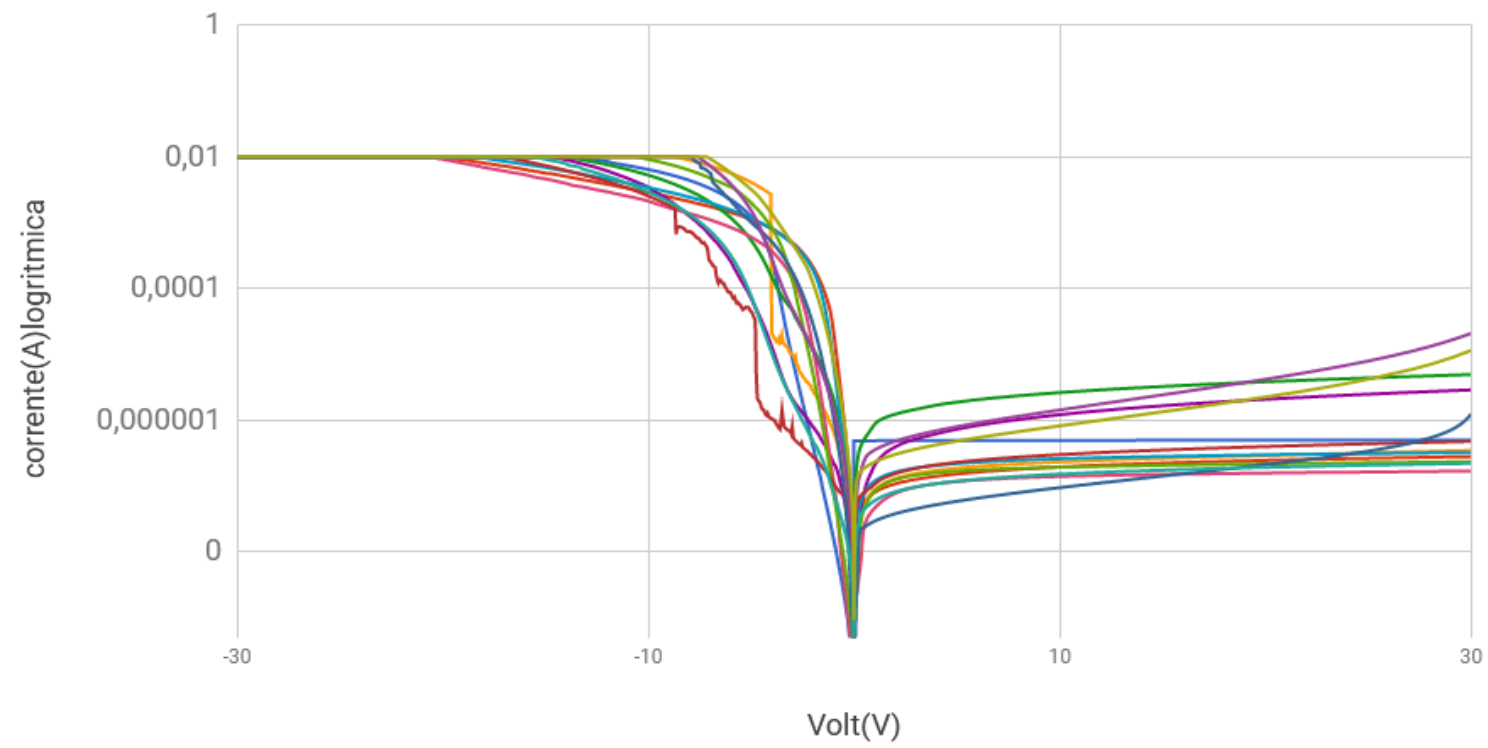


Pode se observar através da Figura 18 que as curvas I xV mostram que a amostra é um diodo do tipo junção p-n, sendo que as amostras teriam o comportamento p por causa do substrato de silício, pois este material é do tipo p, e as amostras como veremos na próxima sessão são do tipo n. Podemos perceber que essa curva é do tipo Shottky, cuja aparência é assimétrica, ou seja, a curva para tensões negativas é desnivelada com relação à curva para tensões positivas.

\subsection{Análise do efeito Hall}

As medições foram feitas no Laboratório de Engenharia de Macromoléculas na Poli USP. Este item contém as medidas de condutividade, resistência e resistividade. Todas as amostras são do tipo n. Os resultados das medições do efeito Hall estão na Tabela 5.

\begin{tabular}{|c|c|c|c|c|c|}
\hline \multicolumn{6}{|c|}{ Tabela 5: Medidas da condutividade, resistividade, resistência e espessura das amostras de } \\
ZnO e suas variáveis de deposição . \\
\hline $\begin{array}{c}\text { Potência } \\
(\mathrm{W})\end{array}$ & $\begin{array}{c}\text { Espessura } \\
(\mathrm{nm})\end{array}$ & $\begin{array}{c}\text { Condutividade } \\
(1 / \text { ohm.cm) }\end{array}$ & $\begin{array}{c}\text { Resistência } \\
\text { (ohm.SQ) }\end{array}$ & $\begin{array}{c}\text { Resistividade } \\
(\text { ohm.cm) }\end{array}$ & lâminas \\
\hline 50 & $26 \pm 1$ & $461 \pm 30$ & $833 \pm 57$ & $(2,2 \pm 0,1) 10^{-3}$ & $\mathrm{~T}$ \\
\hline 100 & $82 \pm 4$ & $105 \pm 23$ & $(1,2 \pm 0,2) 10^{3}$ & $0,010 \pm 0,002$ & $\mathrm{R}$ \\
\hline 50 & $83 \pm 5$ & $227 \pm 103$ & $625 \pm 344$ & $(5 \pm 3) 10^{-3}$ & $\mathrm{U}$ \\
\hline 200 & $84 \pm 13$ & $75 \pm 3$ & $664 \pm 26$ & $(1,34 \pm 0,05) 10^{-2}$ & $\mathrm{~N}$ \\
\hline 50 & $152 \pm 8$ & $0,07 \pm 0,01$ & $(8 \pm 1) 10^{5}$ & $14 \pm 3$ & $\mathrm{D}$ \\
\hline 100 & $392 \pm 22$ & $(1,013 \pm 0,007) 10^{-2}$ & $(2,52 \pm 0,02) 10^{6}$ & $98,7 \pm 0,7$ & $\mathrm{Q}$ \\
\hline 200 & $423 \pm 24$ & $32 \pm 13$ & $816 \pm 342$ & $0,034 \pm 0,016$ & $\mathrm{M}$ \\
\hline 150 & $430 \pm 20$ & $0,009 \pm 0,002$ & $(2,7 \pm 0,6) 10^{6}$ & $115 \pm 25$ & $\mathrm{O}$ \\
\hline 150 & $777 \pm 99$ & $(9,890 \pm 0,003) 10^{-3}$ & $(1,300 \pm 0,004) 10^{6}$ & $101,1 \pm 0,3$ & $\mathrm{G}$ \\
\hline 200 & $1041 \pm 44$ & $(1,14 \pm 0,05) 10^{-2}$ & $(8,5 \pm 0,3) 10^{5}$ & $88 \pm 4$ & $\mathrm{H}$ \\
\cline { 2 - 7 }
\end{tabular}


Tabela 6: Medidas da condutividade, resistividade, resistência e espessura das amostras de $\mathrm{ZnO}$ e suas variáveis de deposição, depositadas em modo $\mathrm{E}$.

\begin{tabular}{|c|c|c|c|c|c|c|}
\hline $\begin{array}{c}\text { Potência } \\
(\mathrm{W})\end{array}$ & $\begin{array}{c}\text { Pressão } \\
(\mathrm{Pa})\end{array}$ & $\begin{array}{c}\text { Espessura } \\
(\mathrm{nm})\end{array}$ & $\begin{array}{c}\text { Condutividade } \\
(1 / \mathrm{ohm} . \mathrm{cm})\end{array}$ & $\begin{array}{c}\text { Resistência } \\
(\text { ohm.SQ) }\end{array}$ & $\begin{array}{c}\text { Resistividade } \\
(\text { ohm.cm) }\end{array}$ & lâminas \\
\hline 50 & 1,3 & $33 \pm 3$ & $0,25 \pm 0,02$ & $(1,0 \pm 0,1) 10^{6}$ & $4,1 \pm 0,3$ & $\mathrm{~J}^{*}$ \\
\hline 50 & 1,3 & $80 \pm 3$ & $0,07 \pm 0,05$ & $(2 \pm 1) 10^{6}$ & $18 \pm 9$ & $\mathrm{~K}^{*}$ \\
\hline 100 & 1,3 & $93 \pm 3$ & $26 \pm 11$ & $(4 . \pm 2) 10^{3}$ & $0,04 \pm 0,02$ & $\mathrm{I}^{*}$ \\
\hline
\end{tabular}

A condutividade das amostras de $\mathrm{ZnO}$ obtidas por efeito Hall apresentaram maior valor para espessuras menores e a resistividade se comporta de forma inversa, resultado esperado conforme a seção 2.2. Na Figura 19 pode se observar este comportamento. Sendo o maior valor de condutividade e resistividade respectivamente, $(461 \pm 30) 1 / \mathrm{ohm} . \mathrm{cm}$ para a lâmina $T$ e (115 \pm 25$)$ ohm.cm para a lâmina $O$. O menor valor de condutividade e resistividade é respectivamente, $\quad(9,890 \pm 0,003) 10^{-3} \quad 1 / \mathrm{ohm} . \mathrm{cm}$ para a lâmina $G$ e $(2,2 \pm 0,1) 10^{-3}$ ohm.cm para a lâmina $T$. Pôde-se perceber através da tabela 6 que as lâminas que foram depositadas com potência de $50 \mathrm{~W}$ em modo $\mathrm{E}$ ( lâminas: $K, J$ ), obtiveram baixos valores de condutividade, decrescendo conforme a espessura aumentava, comportamento esperado pela teoria. 
Figura 19: Gráfico da condutividade e resistividade em função da resistência.

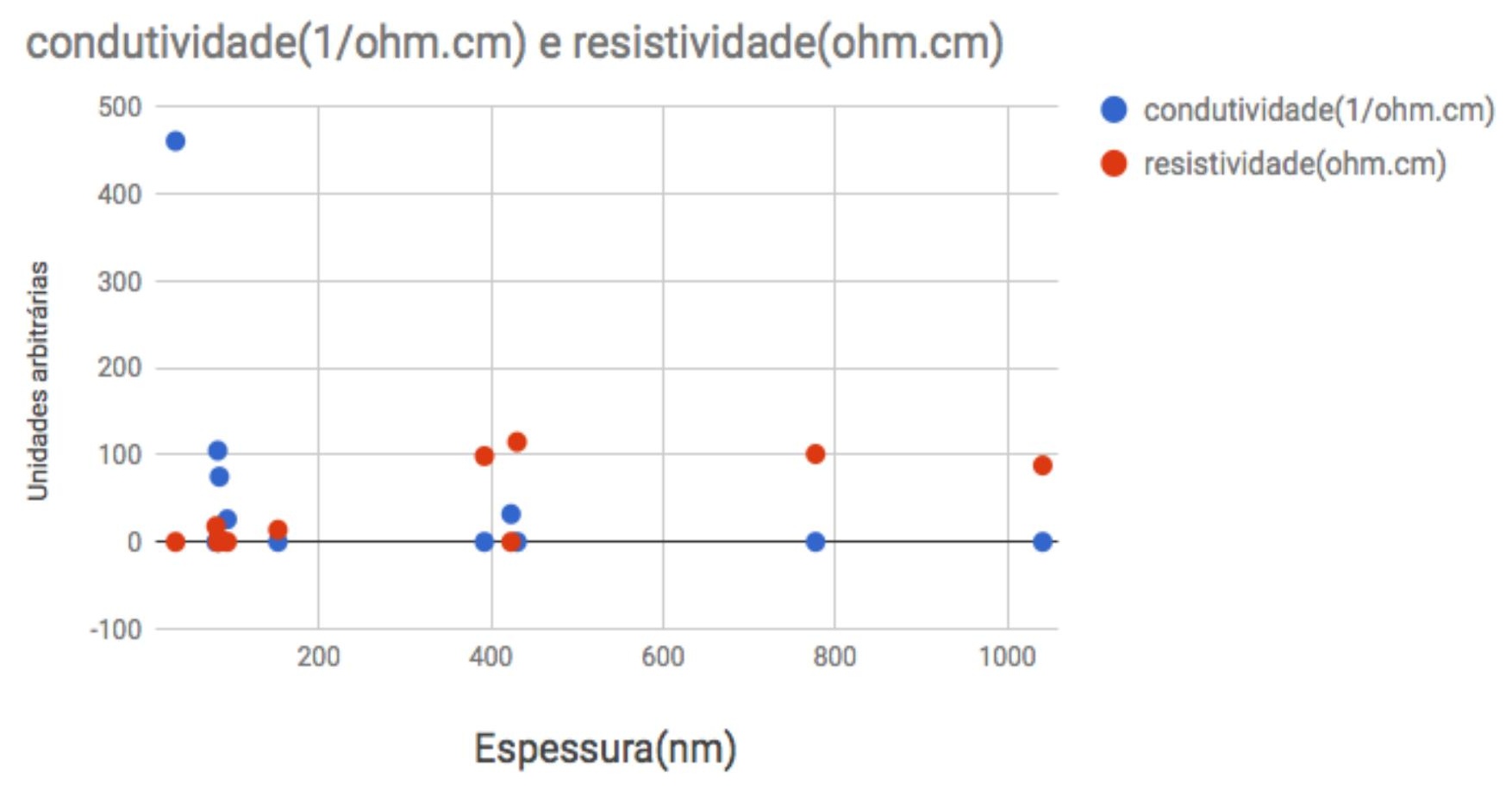

\subsection{Análise das propriedades óticas.}

Este capítulo contém as análises das curvas de reflectância das amostras de $\mathrm{ZnO}$, band gap, e os índices de refração para diferentes potências. Foram utilizados o espectrofotômetro CARY 7000, da Agilent pertencente ao Instituto de Física da USP (LACIFID - Laboratório de cristais iônicos filmes finos e datação) e o interferômetro FILMETRICS F20, no Laboratório de Sistemas Integráveis, LSI, na POLI-USP para obter as cuvas dos espectros de reflectância e o índice de refração, respectivamente. A análise para a transparência será voltada para a região do espectro visível, 400 - $800 \mathrm{~nm}$. Este item foi dividido em sessões para diferentes valores de potência. Lembrando que a análise da transparência será dada pela curva de reflectância, pois o substrato de Si impede a onda de ser transmitida, pois a sua superfície foi polida com qualidade de espelho

\subsubsection{Análise da transparência para potência de $200 \mathrm{~W}$.}

Foi analisado a curva de reflectância em relação ao comprimento de onda incidente para as amostras depositadas a potência de 200W Figura 20. 
Figura 20: Reflectância para amostras produzidas a 200W.

\section{Potência de 200W}

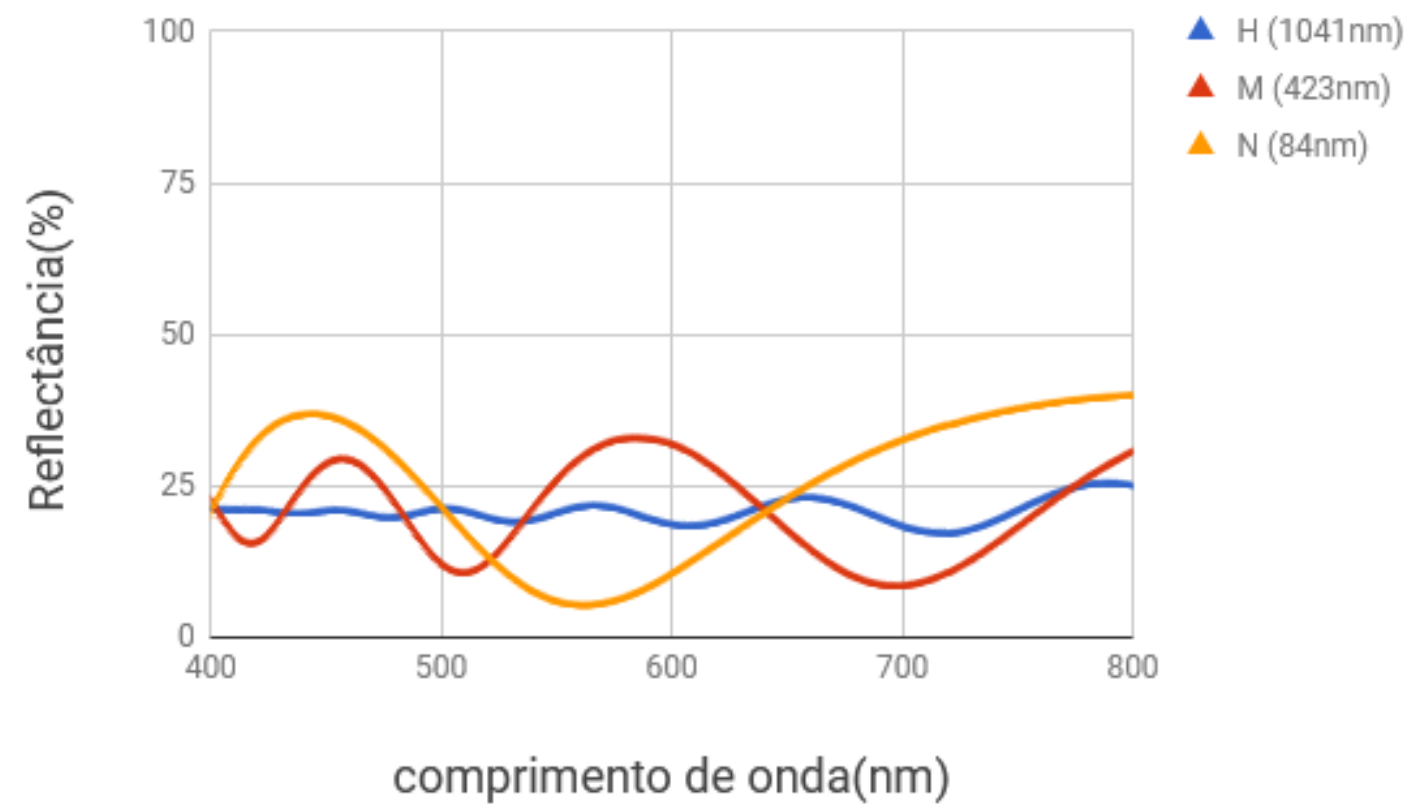

Nota-se que para a potência de $200 \mathrm{~W}$, a reflectância das amostras é baixa, valores menores que $50 \%$. As amostras também têm um comportamento ondulatório, isso se dá devido a alta espessura das mesmas. A amostra $N$ tem uma baixa reflectância bem na região central do espectro visível $(\lambda=600 \mathrm{~nm})$, este baixo percentual demonstra que essa amostra é a pior relativo à transparência em relação às outras depositadas à mesma potência. 


\subsubsection{Análise da transparência para potência de $150 \mathrm{~W}$.}

Foi analisado a curva de reflectância em relação ao comprimento de onda incidente para as amostras depositadas à potência de 150W Figura 21.

Figura 21: Reflectância para amostras produzidas a 150W.

\section{Potência de 150W}

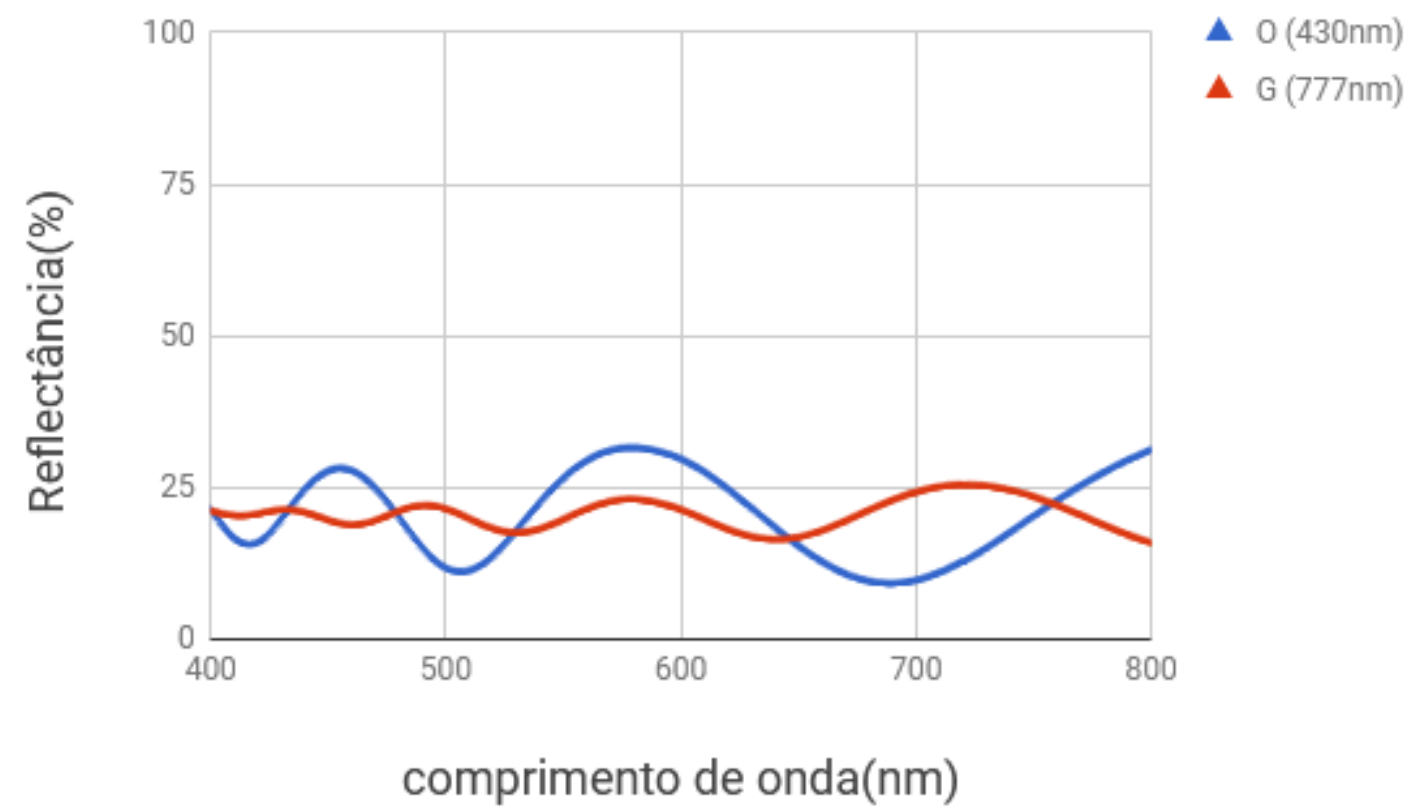

Na figura 21 é possível se observar que as amostras depositadas pela potência de $150 \mathrm{~W}$ possuem um baixo valor de reflectância no espectro visível, portanto não são bons materiais transparentes. Os perfis de reflectância ondulatórios, representam uma amostra de grande espessura (espessura da lâmina $\mathrm{O}=440 \mathrm{~nm}$, espessura da lâmina $\mathrm{G}=777 \mathrm{~nm}$ ). 


\subsubsection{Análise da transparência para potência de $100 \mathrm{~W}$.}

Foi analisado a curva de reflectância em relação ao comprimento de onda incidente para as amostras depositadas a potência de 100W Figura 22.

Figura 22: Reflectância para amostras produzidas a 100W

\section{Potência de $100 \mathrm{~W}$}

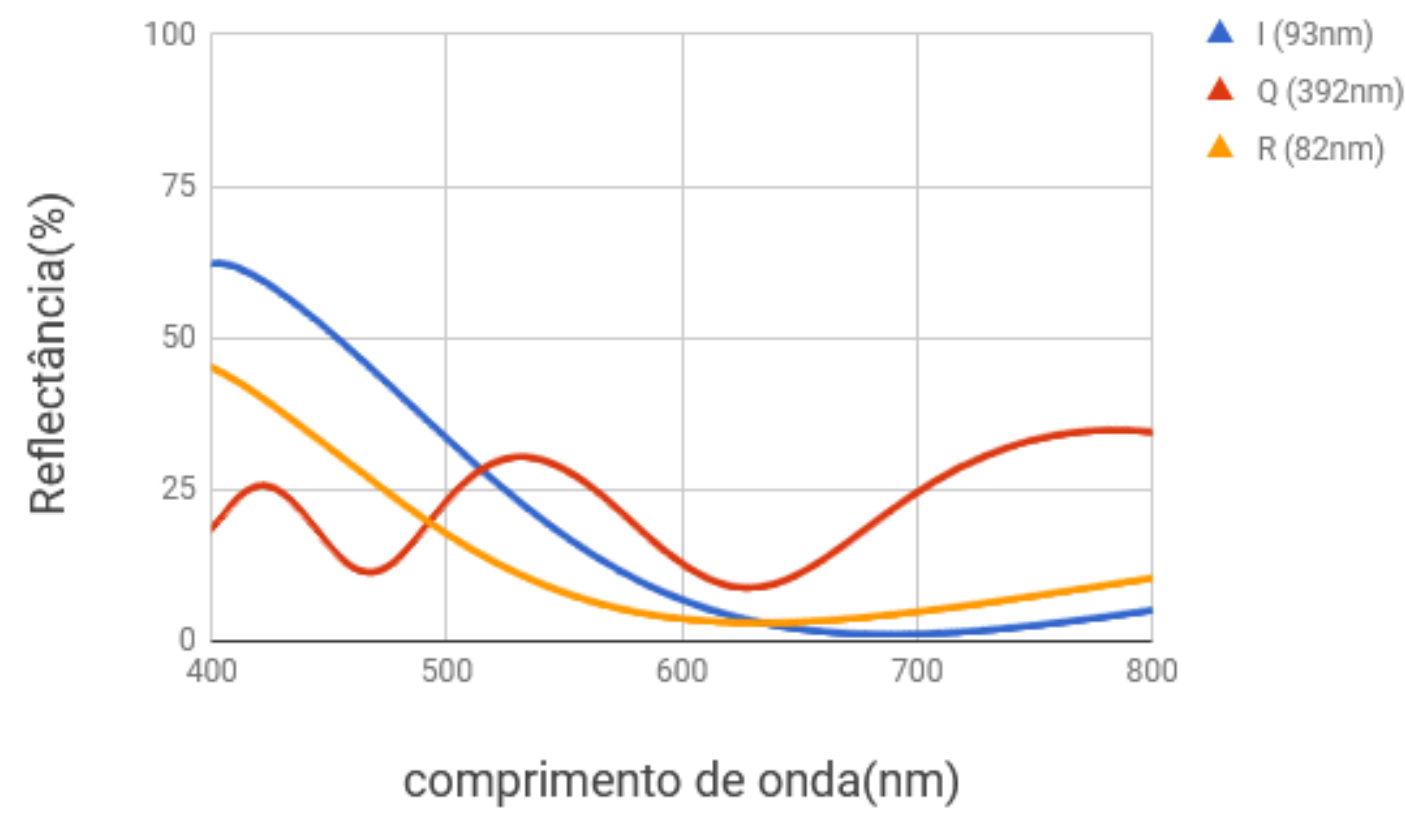

Pode se observar que as amostras depositadas à potência de $100 \mathrm{~W}$ possuem baixa reflectância para o espectro visível. A amostras $Q$ possui um comportamento ondulatório por causa do seu alto valor de espessura (392 nm). A lâmina I foi depositada em modo E, e não apresentou um comportamento diferente das outras lâminas depositadas com a mesma potencia. 


\subsubsection{Análise da transparência para potência de $50 \mathrm{~W}$.}

Foi analisado as curvas de reflectância em relação ao comprimento de onda incidido para a potência de 50W Figura 23.

Figura 23: Reflectância para amostras produzidas a 50W.

\section{Potência de 50W}

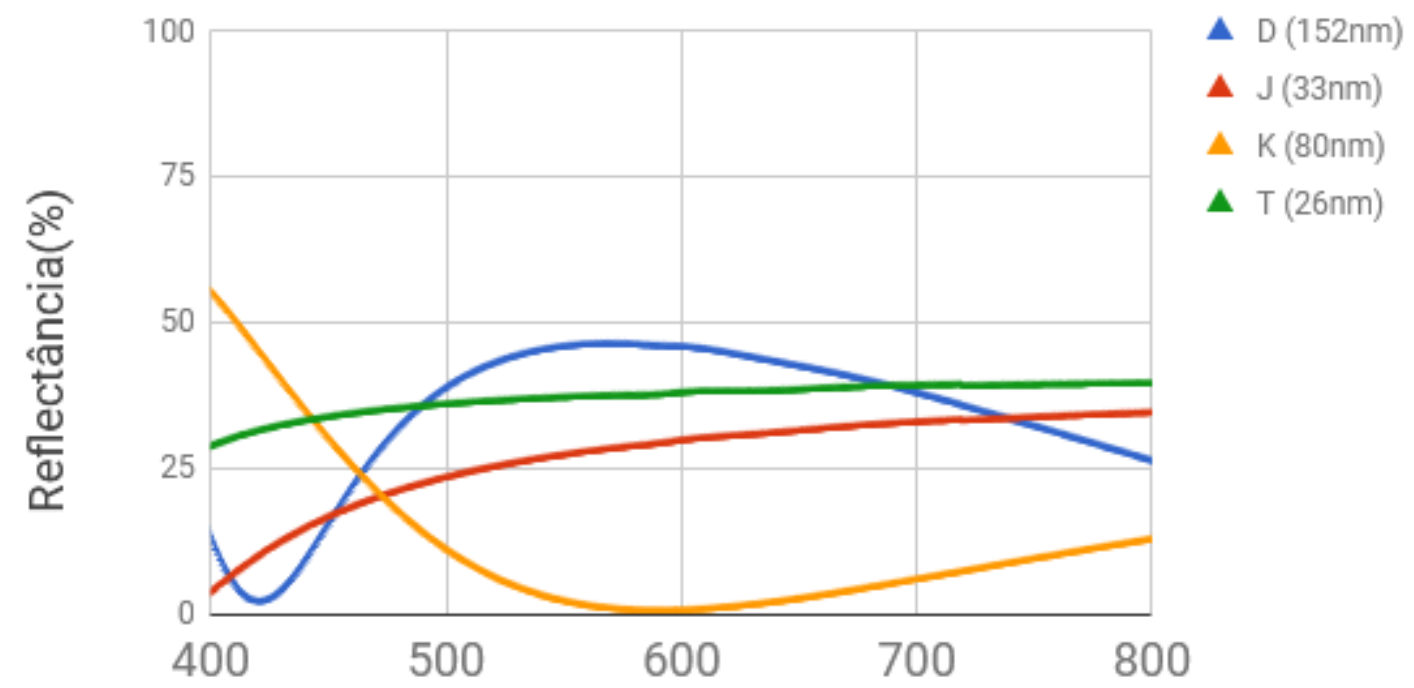

comprimento de onda(nm)

Pode-se observar que as amostras $D$ e $T$ depositadas à potência de $50 \mathrm{~W}$ possuem os maiores valores percentuais de reflectância para o espectro visível, portanto estas amostras podem ser consideradas com as melhores transparências. A lâmina $K$ possue o menor valor percentual de reflectância dentre as amostras da Figura 23, chegando a ter uma porcentagem de reflectancia em torno de $0 \%$ para o comprimento de onda de $600 \mathrm{~nm}$. Isto quer dizer que para esse comprimento de onda, a lâmina absorveu toda radiação incidente. A lâmina J possui uma reflectancia maior que $\mathrm{K}$, mesmo ambas sendo depositadas em modo $\mathrm{E}$, portanto esta característica de deposição não é um fator determinante para a transparência. 


\subsubsection{Band gap e índice de refração}

Os valores do índice de refração obtidos pela técnica de interferometria e do band gap calculado pelo método de Tauc estão listados na Tabela 7.

\begin{tabular}{|c|c|c|c|c|}
\hline \multicolumn{5}{|c|}{ Tabela 7:Valores do índice de refração, band gap e espessuras das amostras de ZnO e suas } \\
variáveis de deposição. & \\
\hline \multirow{2}{*}{ potência(W) } & espessura(nm) & índice de refração & band gap(eV) & lâminas \\
\hline 50 & $26 \pm 1$ & $2,52 \pm 0,09$ & $3,8 \pm 0,3$ & T \\
\hline 50 & $33 \pm 3$ & $2,3 \pm 0,2$ & $3,2 \pm 0,2$ & $\mathrm{~J}^{*}$ \\
\hline 50 & $80 \pm 3$ & $1,964 \pm 0,003$ & $2,146 \pm 0,014$ & $\mathrm{~K}^{*}$ \\
\hline 100 & $82 \pm 4$ & $1,93 \pm 0,12$ & $1,88 \pm 0,02$ & $\mathrm{R}$ \\
\hline 200 & $84 \pm 13$ & $1,2 \pm 0,3$ & $2,7 \pm 0,2$ & $\mathrm{~N}$ \\
\hline 100 & $93 \pm 3$ & $1,981 \pm 0,014$ & $1,79 \pm 0,02$ & $\mathrm{I}^{*}$ \\
\hline 50 & $152 \pm 8$ & $2,15 \pm 0,07$ & $2,89 \pm 0,11$ & $\mathrm{D}$ \\
\hline 100 & $392 \pm 22$ & $1,58 \pm 0,08$ & $2,3 \pm 0,2$ & $\mathrm{Q}$ \\
\hline 200 & $423 \pm 24$ & $1,64 \pm 0,10$ & $2,54 \pm 0,07$ & $\mathrm{M}$ \\
\hline 150 & $430 \pm 20$ & $1,56 \pm 0,08$ & $2,52 \pm 0,07$ & $\mathrm{O}$ \\
\hline 150 & $777 \pm 99$ & $1,57 \pm 0,03$ & $3,1 \pm 0,2$ & $\mathrm{G}$ \\
\hline 200 & $1041 \pm 44$ & $1,58 \pm 0,02$ & $1,22 \pm 0,02$ & $\mathrm{H}$ \\
\hline
\end{tabular}

Os índices de refração obtidos por interferometria apresentaram padrão de comportamento inversamente proporcional em relação à espessura. Quanto maior os valores dos índices de refração, menor os valores da espessura Figura 24. Sendo o maior valor do índice de refração de 2,52 $\pm 0,09$ para a lâmina $T$ de menor espessura e o menor valor de 1,2 $\pm 0,3$ para a lâmina $H$ de maior espessura. A análise dos resultados mostra uma tendência de o band gap aumentar conforme a espessura da amostra aumenta. Sendo o maior valor do band gap de 3,8 $\pm 0,3 \mathrm{eV}$ para a lâmina T e o menor valor de 1,22 $\pm 0,02$ para a lâmina $H$. 
Figura 24: Relação entre os índices de refração e a espessura.

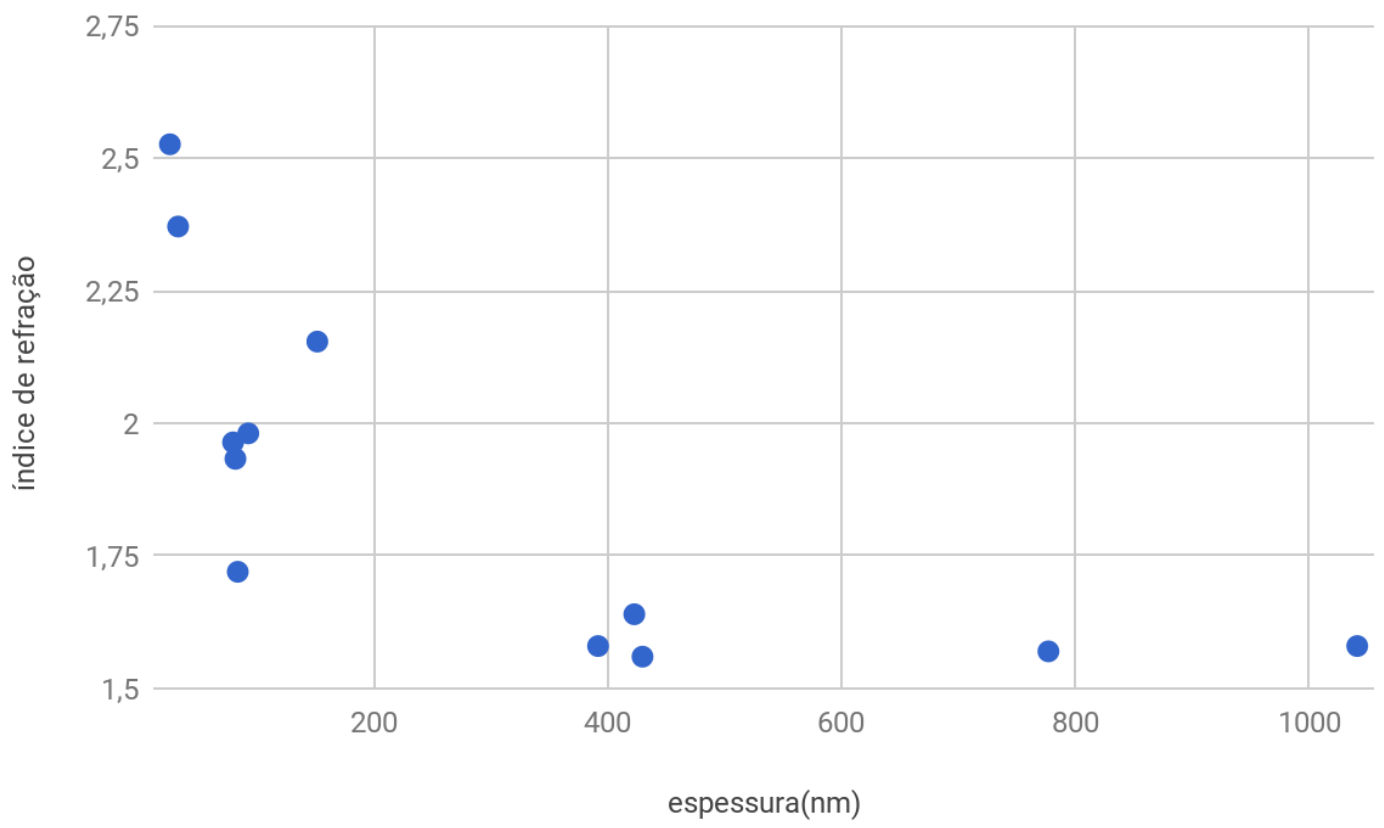

\subsubsection{Comentários gerais}

Foi notado que os maiores valores para a reflectância foram obtidos para amostras produzidas a menor potência, e a deposição de baixa densidade de plasma, não influenciou de modo significativo para a transparência.

O comportamento ondulatório foi observado para amostras que mostraram um alto valor de espessura. As amostras com os maiores índices de refração apresentaram maior reflectância, resultado coerente com a teoria, pois quanto maior o índice de refração, maior a reflexão que a luz incidente sofrerá no material. 


\subsection{Figura de mérito}

Os valores da figura de mérito foram calculados com base nos valores da reflectância obtidos no espectofotometro. Como o filme foi depositado em um substrato de silício, não foi possível obter a curva de transmitância, pois o silício não é transparente. A Tabela 8 contêm os valores da figura de mérito para cada amostra, assim como o valor da reflectância, resistências e potência de deposição.

\begin{tabular}{|c|c|c|c|c|}
\hline \multicolumn{5}{|c|}{ Tabela 8: Valores da figura de mérito, das resistências da folha, reflectância e } \\
potência de deposição.
\end{tabular}

Os valores da figura de mérito apresentam os melhores resultados para as lâminas M, R, I e T. A lâmina que possui o melhor valor para a figura de mérito foi a lâmina $\mathrm{T}$ com o valor de $(1,5 \pm 0,3) 10^{-7} \Omega^{-1}$, e o valor mais baixo é de $(1,4 \pm 0,5) 10^{-13} \Omega^{-1}$ para a lâmina G. Os melhores resultados foram obtidos para as amostras depositadas a menor potência. 


\section{Conclusões}

A série de amostras produzidas por magnetron sputtering no âmbito deste projeto apresentaram uma estequiometria próxima da estequiometria do alvo de $\mathrm{ZnO}$ utilizado.

As amostras produzidas pelo modo E apresentaram menor taxa de deposição em relação ao conjunto das amostas estudadas.

Todas as amostras produzidas foram caracterizadas como Schottky tipo n.

Os filmes mais finos, produzidos a baixa potência, apresentaram maiores valores para a condutividade e menores valores para a constante dielétrica, tornando esses filmes com melhores caracteristcas elétricas.

As amostras depositadas a baixa potência apresentaram maior transparência e melhores valores da figura de mérito.

O método de produção de filmes finos por magnetron sputtering demonstrou grande potencial para o desenvolvimento de óxido de zinco para aplicação como TCO. 


\section{Trabalhos futuros}

Realizar estudos do efeito da cristalinidade dos filmes de $\mathrm{ZnO}$ sobre as propriedades físicas dos materiais estudadas neste projeto.

Produzir amostras dopadas com vários elementos para o controle dos filmes tipo Shottky ou Ohmico através das características do método de magnetron sputtering.

Produzir amostras a diferentes pressões na câmara do sistema de magnetron sputtering para melhorar o controle sobre a espessura e propriedades dos filmes produzidos.

Produzir filmes finos de óxido de zinco por outros métodos, como IBAD (Ion Beam Assisted Deposition), para estudos comparativos e melhoria na qualidade do material produzido.

Produzir filmes finos de $\mathrm{ZnO}$ sobre substratos transparentes para ampliar o controle sobre as propriedades óticas dos materiais produzidos. 


\section{Referências bibliográficas}

${ }^{1}$ CHOPRA, K. L.; MAJOR, S.; PANDYA, D. K. Transparent conductors-a status review. Thin solid films, v. 102, n. 1, p. 1-46, 1983.

${ }^{2}$ HOSONO, Hideo; PAINE, David C. Handbook of transparent conductors. Springer Science \& Business Media, 2010.

${ }^{3}$ PACHAURI, Rajendra K. et al. Climate change 2014: synthesis report. Contribution of Working Groups I, II and III to the fifth assessment report of the Intergovernmental Panel on Climate Change. IPCC, 2014.

${ }^{4}$ RAVICHANDRAN, K. et al. Properties of sprayed aluminum-doped zinc oxide films - a review. Materials and Manufacturing Processes, v. 31, n. 11, p. 1411-1423, 2016.

${ }^{5}$ Enciclopaedia Britannica Online Academic Edition. Zincite. Disponível em: $<$ http://www.britannica.com/EBchecked/topic/657376/zincite $>$. Acesso em: 02 de fevereiro de 2018.

${ }^{6}$ WELLINGS, J. S. et al. Growth and characterisation of electrodeposited $\mathrm{ZnO}$ thin films. Thin solid films, v. 516, n. 12, p. 3893-3898, 2008.

${ }^{7} \mathrm{SAHAL}, \mathrm{M}$. et al. Structural, electrical and optical properties of $\mathrm{ZnO}$ thin films deposited by sol-gel method. Microelectronics Journal, v. 39, n. 12, p. 1425-1428, 2008.

${ }^{8}$ VAN DE POL, Frans CM. Thin film ZnO-properties and applications. American Ceramic Society Bulletin, n. 69, p. 1959-1965, 1990.

${ }^{9}$ PEARTON, S. J. et al. Recent progress in processing and properties of ZnO. Progress in materials science, v. 50, n. 3, p. 293-340, 2005.

${ }^{10}$ LEE, Jin-Hong; KO, Kyung-Hee; PARK, Byung-Ok. Electrical and optical properties of $\mathrm{ZnO}$ transparent conducting films by the sol-gel method. Journal of Crystal Growth, v. 247, n. 1-2, p. 119-125, 2003.

${ }^{11}$ DE MATOS, PAULO CESAR. Influência das propriedades estruturais e parâmetros de deposição sobre a dureza e a tensão (stress) intrínseca dos filmes finos amorfos de carbononitrogênio. Universidade do Vale do Paraíba, Instituto de pesquisas e Desenvolvimento. Dissertação (Mestrado em Física e Astronomia). São José dos Campos. SP, 2006.

${ }^{12}$ ESPITIA, Paula Judith Perez et al. Zinc oxide nanoparticles: synthesis, antimicrobial activity and food packaging applications. Food and Bioprocess Technology, v. 5, n. 5, p. 14471464, 2012.

${ }^{13}$ WEINTRAUB, Benjamin et al. Density-controlled, solution-based growth of $\mathrm{ZnO}$ nanorod arrays via layer-by-layer polymer thin films for enhanced field emission. Nanotechnology, v. 19, n. 43, p. 435302, 2008.

${ }^{14}$ SILVA, Luciane Janice Venturini da et al. Produção e caracterização de filmes finos de ZnO. 2010.

${ }^{15} \mathrm{JIAO}, \mathrm{S}$. J. et al. $\mathrm{ZnO} \mathrm{p}-\mathrm{n}$ junction light-emitting diodes fabricated on sapphire substrates. Applied physics letters, v. 88, n. 3, p. 031911, 2006.

${ }^{16} \mathrm{BAE}$, Chang Hyun et al. Array of ultraviolet luminescent $\mathrm{ZnO}$ nanodots fabricated by pulsed laser deposition using an anodic aluminium oxide template. Nanotechnology, v. 17, n. 2, p. $381,2005$. 
${ }^{17}$ LIU, Huiyong et al. Transparent conducting oxides for electrode applications in light emitting and absorbing devices. Superlattices and Microstructures, v. 48, n. 5, p. 458-484, 2010.

${ }^{18}$ BATOP Optoelectronics. SOC - Saturable Output Coupler. Disponível em: < http://www.batop.com/information/SOC_infos.html >. Acesso em: 01 de fevereiro de 2018.

${ }^{19}$ GUILLÉN, C.; HERRERO, J. Polycrystalline growth and recrystallization processes in sputtered ITO thin films. Thin Solid Films, v. 510, n. 1-2, p. 260-264, 2006.

${ }^{20}$ HASSANIEN, Ahmed Saeed; AKL, Alaa A. Influence of composition on optical and dispersion parameters of thermally evaporated non-crystalline Cd50S50- xSex thin films. Journal of Alloys and Compounds, v. 648, p. 280-290, 2015.

${ }^{21}$ LÓPEZ, Rosendo; GÓMEZ, Ricardo. Band-gap energy estimation from diffuse reflectance measurements on sol-gel and commercial TiO2: a comparative study. Journal of sol-gel science and technology, v. 61, n. 1, p. 1-7, 2012.

${ }^{22}$ HAAKE, G. New figure of merit for transparent conductor. Appl. Phys. 47, 40864089(1976)

${ }^{23} \mathrm{GAO}$, Wei; LI, Zhengwei. $\mathrm{ZnO}$ thin films produced by magnetron sputtering. Ceramics International, v. 30, n. 7, p. 1155-1159, 2004.

${ }^{24}$ KELLY, P. J.; ARNELL, R. D. Magnetron sputtering: a review of recent developments and applications. Vacuum, v. 56, n. 3, p. 159-172, 2000.

${ }^{25}$ OXFORD VACUUM SCIENCE. Sputter deposition. Disponível em: $<$ http://www.oxford-vacuum.com/background/thin_film/sputtering.htm>. Acesso em: $14 \mathrm{de}$ setembro de 2012.

${ }^{26}$ DAMIANI, Larissa Rodrigues. Filmes de óxido de zinco e nitreto de zinco depositados por magnetron sputtering com diferentes pressões de argônio, oxigênio e nitrogênio. Tese de Doutorado. Universidade de São Paulo.

${ }^{27}$ TABACNIKS, Manfredo H. Análise de Filmes Finos por PIXE e RBS. Instituto de Física-USP, 1997.

${ }^{28}$ SANTOS, Thales Borrely dos. Controle de propriedades de filmes finos de óxido de alumínio através da assistência de feixe iônico. Diss. Universidade de São Paulo.

${ }^{29}$ THIN FILMS MEASUREMENT, FILMETRICS

${ }^{30}$ MARTINO, João Antônio; PAVANELLO, Marcelo Antonio; VERDONCK, Patrick Bernard. Caracterização elétrica de tecnologia e dispositivos MOS. Cengage Learning Editores, 2004. 